NBER WORKING PAPER SERIES

\title{
CENTRAL BANK COMMUNICATION \\ AND POLICY EFFECTIVENESS
}

\author{
Michael Woodford \\ Working Paper 11898 \\ http://www.nber.org/papers/w11898
}

\author{
NATIONAL BUREAU OF ECONOMIC RESEARCH \\ 1050 Massachusetts Avenue \\ Cambridge, MA 02138 \\ December 2005
}

Presented at the Federal Reserve Bank of Kansas City Symposium IThe Greenspan Era: Lessons for the Future," Jackson Hole, Wyoming, August 25-27, 2005. I would like to thank Charlie Bean, Ben Bernanke, Alan Blinder, Michael Ehrmann, Marcel Fratzscher, Charles Goodhart, Larry Meyer, and Anders Vredin for helpful comments on an earlier draft, without implicating any of them in the views expressed here. I would also like to thank Mauro Roca for research assistance and the National Science Foundation for research support through a grant to the NBER. The views expressed herein are those of the author(s) and do not necessarily reflect the views of the National Bureau of Economic Research.

(C)2005 by Michael Woodford. All rights reserved. Short sections of text, not to exceed two paragraphs, may be quoted without explicit permission provided that full credit, including () notice, is given to the source. 
Central Bank Communication and Policy Effectiveness

Michael Woodford

NBER Working Paper No. 11898

December 2005

JEL No. E52, E58

\begin{abstract}
A notable change in central banking over the past 15 years has been a world-wide movement toward increased communication by central banks about their policy decisions, the targets that they seek to achieve through those decisions, and the central bank's view of the economy's likely future evolution. This paper considers the role of such communication in the successful conduct of monetary policy, with a particular emphasis on an issue that remains controversial: to what extent is it desirable for central banks to comment on the likely path of short-term interest rates?
\end{abstract}

After reviewing general arguments for and against central-bank transparency, the paper considers two specific contexts in which central banks have been forced to consider how much they are willing to say about the future path of interest rates. The first is the experiment with policy signaling by the FOMC in the U.S., using the statement released following each Committee meeting, since August 2003. The second is the need to make some assumption about future policy when producing the projections (for future inflation and other variables) that are central to inflation-forecast targeting procedures, of the kind used by the Bank of England, the Swedish Riksbank, the Reserve Bank of New Zealand, and others. In both cases, it is argued that increased willingness to share the central bank's own assumptions about future policy with the public has increased the predictability of policy, in ways that are likely to have improved central bank's ability to achieve their stabilization objectives.

Michael Woodford

Department of Economics

Columbia University

1009B I.A.B., mc3308

New York, NY 10027

and NBER

mw2230@ columbia.edu 
One of the most notable changes at the Federal Reserve during the tenure of Alan Greenspan as Chairman of the Board of Governors has been a steady increase in the FOMC's willingness to talk openly about the policy decisions that it has made and those it is likely to make in the future. Before the 1990s, central banking was shrouded in mystery, at the Fed as elsewhere. The title of William Greider's 1987 bestseller about the Fed - Secrets of the Temple - gives an idea of the common perception of the institution at the beginning of the Greenspan era. This "mystique" of central banking was jealously guarded by central bankers - as the epigraph indicates - as essential to their success.

Things have changed rapidly over the past 15 years, both at the Fed and elsewhere. Indeed, St. Louis Fed President William Poole (2005) lists the increase in transparency, and the consequent increase in the predictability of monetary policy, as one of the four defining characteristics of "the Greenspan policy regime." Before 1994, the FOMC made no public announcement regarding its target for the federal funds rate following the meetings at which the target was determined; markets had to try to infer the target rate from the type and size of open-market operations that were subsequently conducted by the Trading Desk in New York to implement the policy. According to Poole, "before Greenspan many within the Fed believed that policy effectiveness depended on taking markets by surprise." But since February 1994, the FOMC has issued a public statement following each meeting at which the target has been changed, indicating the new target rate. The FOMC has also been increasingly willing to give advance signals of the likely future stance of policy. Beginning in December 1998, the FOMC began to include in the post-meeting statement an assessment of the FOMC's current "bias" with respect to possible changes in the stance of policy; in December 1999, the Committee decided that from then on it would issue a statement after every meeting, whether policy was changed or not, and that this would include a "balance of risks" assessment, understood to refer to a time horizon extending beyond the next Committee meeting. Since August 2003 - as is discussed further in section 2 - the post-meeting statements have included even more explicit statements about the likely future path of interest rates. This aspect of the statement now attracts considerable attention, in financial markets and in the financial press. Most recently, the FOMC has moved to expedite the release of the minutes of its deliberations, so that these are now available to the public before the next Committee meeting. This too has facilitated public understanding of current policy, and helped to increase the clarity with which the FOMC is able to explain its 
view of the likely future path of policy.

Poole argues that the "improved predictability of policy [under Greenspan] has had much to do with improved effectiveness of policy." Is there reason to believe that this is true? And more specifically, does the Fed's bold recent experiment in greater explicitness about the future outlook for interest rates represent an innovation that should be expected to further enhance the effectiveness of policy, or does it represent a step too far? ${ }^{1}$

I shall begin by reviewing the general case for the importance of effective communication for effective monetary policy, and then ask, in the light of these general considerations, to what extent it makes sense for a central bank to be willing to make public statements about future policy. I then discuss in further detail two specific contexts in which central banks have recently given a great deal of attention to the question of how much they should talk about the future path of interest rates. The first is the Fed's experiment with policy signaling since August 2003, already mentioned. The second concerns the assumption about future policy that should be used in projections of the economy's likely future evolution that are made public. This has been a particularly crucial issue for the inflation-forecast targeting central banks, for reasons discussed further in section 3; but the issue is also being debated within the Federal Reserve System, especially among those considering the possibility of inflation targeting in the United States.

\section{Why Communication Matters}

The importance of communication strategy for policy effectiveness follows from a fundamental feature of the kind of problem that a central bank is called upon to solve. Central banking is not like steering an oil tanker, or even guiding a spacecraft, which follows a trajectory that depends on constantly changing factors, but that does not depend on the vehicle's own expectations about where it is heading. Because the key decisionmakers in an economy are forward-looking, central banks affect the economy as much through their influence on expectations as through any direct, mechanical effects of central bank trading in the market for overnight cash. As a consequence, there is good reason for a central bank to commit itself to a systematic approach to

\footnotetext{
${ }^{1}$ Even William Poole, in the remarks just cited, refrains from taking a stand on this last issue.
} 
policy, that not only provides an explicit framework for decisionmaking within the bank, but that is also used to explain the bank's decisions to the public.

\subsection{Central Banking as Management of Expectations}

It is important for the public to understand the central bank's actions, to the greatest extent possible, not only for reasons of democratic legitimacy — though this is an excellent reason itself, given that central bankers are granted substantial autonomy in the execution of their task - but also in order for monetary policy to be most effective. For not only do expectations about policy matter, but, at least under current conditions, very little else matters. Few central banks of major industrial nations still make much use of credit controls or other attempts to directly regulate the flow of funds through financial markets and institutions. Increases in the sophistication of the financial system have made it more difficult for such controls to be effective, and in any event the goal of improvement of the efficiency of the sectoral allocation of resources stressed above would hardly be served by such controls, which (if successful) inevitably create inefficient distortions in the relative cost of funds to different parts of the economy.

Instead, banks restrict themselves to interventions that seek to control the overnight interest rate in an interbank market for central-bank balances (for example, the federal funds rate in the U.S.). But the current level of overnight interest rates as such is of negligible importance for economic decisionmaking; if a change in the overnight rate were thought to imply only a change in the cost of overnight borrowing for that one night, then even a large change (say, a full percentage point increase) would make little difference to anyone's spending decisions. The effectiveness of changes in central-bank targets for overnight rates in affecting spending decisions (and hence ultimately pricing and employment decisions) is wholly dependent upon the impact of such actions upon other financial-market prices, such as longer-term interest rates, equity prices and exchange rates. These are plausibly linked, through arbitrage relations, to the short-term interest rates most directly affected by central-bank actions; but it is the expected future path of short-term rates over coming months and even years that should matter for the determination of these other asset prices, rather than the current level of short-term rates by itself. ${ }^{2}$

\footnotetext{
${ }^{2}$ Gurkaynak (2005) finds that what he calls "timing surprises" — unexpected changes in the
} 
Thus the ability of central banks to influence expenditure, and hence pricing, decisions is critically dependent upon their ability to influence market expectations regarding the future path of overnight interest rates, and not merely their current level. Better information on the part of market participants about central-bank actions and intentions should increase the degree to which central-bank policy decisions can actually affect these expectations, and so increase the effectiveness of monetary stabilization policy. Insofar as the significance of current developments for future policy are clear to the private sector, markets can to a large extent "do the central bank's work for it," in that the actual changes in overnight rates required to achieve the desired changes in incentives can be much more modest when expected future rates move as well. ${ }^{3}$

Thus the public's understanding, not only of what the central bank is currently doing, but of what it can be expected to do in the future, is critical for the effectiveness of policy. It might nonetheless be argued that it should be enough for a central bank to systematically follow a sound policy, without also needing to explain it to the public. If one assumes rational expectations on the part of the public, it would follow that any systematic pattern in the way that policy is conducted should be correctly inferred from the bank's observed behavior. Yet while it would be unwise to choose a policy the success of which depends on its not being understood by the public — which is the reason for choosing a policy rule that is associated with a desirable rational-expectations equilibrium - it is at the same time prudent not to rely too

current federal funds rate operating target that do not involve any change in market expectations regarding what the funds rate target will be after the next meeting, as when a change in the target that was already expected occurs sooner than some had expected it - have little effect on either bond yields or equity prices, while FOMC post-meeting statements that change expectations regarding the future path of the funds rate have significant effects on both.

${ }^{3}$ There is evidence that this is already happening, as a result both of greater sophistication on the part of financial markets and greater transparency on the part of central banks, the two developing in a sort of symbiosis with one another. Blinder et al. (2001, p. 8) argue that in the period from early 1996 through the middle of 1999, one could observe the U.S. bond market moving in response to macroeconomic developments that helped to stabilize the economy, despite relatively little change in the level of the federal funds rate, and suggest that this reflected an improvement in the bond market's ability to forecast Fed actions before they occur. Statistical evidence of increased forecastability of Fed policy by the markets is provided by Lange et al. (2001), who show that the ability of Treasury bill yields to predict changes in the federal funds rate some months in advance has increased since the late 1980s. 
heavily on the assumption that the public will understand policy perfectly regardless of the efforts that are made to explain it. Insofar as explanation of the policy rule to the public does no harm under the assumption of rational expectations, but improves outcomes under the (more realistic) assumption that a correct understanding of the central bank's policy commitments does not occur automatically, then it is clearly desirable for the central bank to explain the rule that it follows. ${ }^{4}$

The advantages of a public target when the private sector must otherwise forecast future policy by extrapolating from experience are shown in a recent analysis by Orphanides and Williams (2005). In the Orphanides-Williams model, private agents forecast inflation using a linear regression model, the coefficients of which are constantly re-estimated using the most recent observations of inflation. The assumption of forecasting in this manner (on the basis of a finite time-window of historical observations) rather than a postulate of rational expectations worsens the tradeoff between inflation variability and output-gap variability that is available to the central bank. ${ }^{5}$ Allowing inflation variations in response to "cost-push" shocks for the sake of outputgap stabilization is more costly than it would be under rational expectations, because temporary inflation fluctuations in response to the shocks can be misinterpreted as indicating different inflation objectives on the part of the central bank. Orphanides and Williams then show that a credible commitment to a long-run inflation target so that private agents do not need to estimate the long-run average rate of inflation, but only the dynamics of transitory departures from it - allows substantially better stabilization outcomes, though still not quite as good as if private agents were to fully understand the equilibrium dynamics implied by the central bank's policy rule. This provides a nice example of theoretical support for the interpretation given by Mervyn

\footnotetext{
${ }^{4} \mathrm{King}(2005 \mathrm{~b})$ proposes that it is more reasonable to expect the public to follow simple (but possibly fairly robust) "heuristics" in making decisions, of the kind discussed by Gigerenzer and Selten (2001), rather than behaving like the optimizing agents of economic theory. He argues that in this case central-bank communication can play an important role in leading people to choose heuristics of the right sort - i.e., ones that lead to greater macroeconomic stability.

${ }^{5}$ Eusepi (2005) finds in the context of a model with more detailed microfoundations that requiring private agents to learn equilibrium patterns of fluctuations in inflation and the output gap by estimating atheoretical regressions can lead to instability of the learning dynamics and to persistent fluctuations driven by learning dynamics; transparency about the form of the central bank's policy rule (so that agents can estimate a correctly specified structural equation instead of a reduced-form econometric model) instead favors stability of the learning dynamics.
} 
King (2005a) and others of practical experience with inflation targeting, which is that tighter anchoring of the public's inflation expecations has made possible greater stability of both real activity and inflation.

Nor is there any reason to suppose that it suffices for a central bank to make clear the long-run average inflation rate that it intends to maintain, while allowing the public to reach its own conclusions about the nature of transitory departures of the inflation rate from that long-run average. It is certainly true that anchoring expectations about the long-run average inflation rate is important, and that in itself is an important accomplishment. But the analysis of Orphanides and Williams also shows that even when private agents know the long-run average, but have to estimate the dynamics of transitory departures from it, the available tradeoff between inflation stabilization and output-gap stabilization is less favorable than it would be under rational expectations, i.e., than it would be if one could rely on a correct understanding of the transitory dynamics. Thus there are in principle gains from an explicit commitment regarding this aspect of policy as well, and not simply trusting that people will be able to observe the pattern in one's behavior.

There is also a further, somewhat subtler, reason why explicit commitment to a target or policy rule is desirable, given the forward-looking behavior of the people in the economy that one seeks to stabilize. Even if one supposes that the private sector will fully understand whatever approach to policy the central bank takes, regardless of what it says about it, a public commitment to a rule can help policymakers to conduct policy in a way that achieves better outcomes. For is not enough that a central bank have sound objectives (reflecting a correct analysis of social welfare), that it make policy in a systematic way, using a correct model of the economy and a staff that is well-trained in numerical optimization, and that all this be explained thoroughly to the public. A bank that approaches its problem as one of optimization under discretion - deciding afresh on the best action in each decision cycle, with no commitment regarding future actions except that they will be the ones that seem best in whatever circumstances may arise - can still obtain a substantially worse outcome, from the point of view of its own objectives, than one that commits itself to follow a properly chosen policy rule. As Kydland and Prescott (1977) first showed, this can occur even when the central bank has a correct quantitative model of the policy tradeoffs that it faces at each point in time, and the private sector has correct expectations about the way that policy will be conducted. 
At first thought, discretionary optimization might seem exactly what one would want an enlightened central bank to do. All sorts of unexpected events constantly occur that affect the determination of inflation and real activity, and it is not hard to see that, in general, the optimal level of interest rates at any point in time should depend on precisely what has occurred. It is plainly easiest, as a practical matter, to arrange for such complex state-dependence of policy by having the instrument setting at a given point in time be determined only after the unexpected shocks have already been observed. Furthermore, it might seem that the dynamic programming approach to the solution of intertemporal optimization problems provides justification for an approach in which a planning problem is reduced to a series of independent choices at each of a succession of decision dates.

But standard dynamic programming methods are valid only for the optimal control of a system that evolves mechanically in response to the current action of the controller. The problem of monetary stabilization policy is of a different sort, in that the consequences of the central bank's actions depend not only upon the sequence of instrument settings up until the present time, but also upon private-sector expectations regarding future policy. In such a case, sequential (discretionary) optimization leads to a sub-optimal outcome because at each decision point, prior expectations are taken as given, rather than as something that can be affected by policy. Nonetheless, the predictable character of the central bank's decisions, taken from this point of view, do determine the (endogenous) expectations of the private sector at earlier dates, under the hypothesis of rational expectations; a commitment to behave differently, that is made credible to the private sector, could shape those expectations in a different way, and because expectations matter for the determination of the variables that the central bank cares about, in general outcomes can be improved through shrewd use of this opportunity. This is illustrated concretely in section 2, when I discuss the way in which policy should be conducted when the lower bound on short-term nominal interest rates constrains the way that policy can be conducted.

In general, the most effective policy (the best outcome, from among the set of possible rational-expectations equilibria) requires that policy be conducted in a historydependent way, so that policy at any time depends not only on conditions then (and what it is considered possible to achieve from then on), but also on past conditions, even though these no longer constrain what it is possible to achieve in the present. While there is no benefit, at the time, from conducting policy in a way that is condi- 
tioned by the past, the anticipation that one would do so, at an earlier date, can have important beneficial effects on what policy can achieve at the earlier date. These benefits can make the subsequent losses worthwhile, as the example in the next section shows.

It is furthermore desirable, not simply that a central bank have a private intention of this sort, but that it be publicly committed to such a target. First, a public commitment is likely to make it easier for the central bank's policy deliberations to remain focused on the right criterion - the one with the property that systematic conformity to it leads to an optimal equilibrium — rather than being tempted to "let bygones be bygones." And second, the benefits associated with commitment to a history-dependent policy depend entirely on this aspect of policy being anticipated by the private sector; otherwise, it would be rational to "let bygones be bygones." There is no point to a secret commitment to the future conduct of policy in accordance with a history-dependent rule, while the private sector continues to believe that the central bank will act in a purely forward-looking fashion; thus the target should be explained as clearly as possible to the public, and shown to be guiding the bank's decisions.

\subsection{Communication About What?}

Which specific types of communication by central banks are most important, in light of the objectives discussed above? It is possible to distinguish among at least four broad classes of issues, about which a central bank may consider revealing more or less to the public. The first is the central bank's interpretation of economic conditions, including (perhaps) the central bank's view of the outlook for the future, to the extent that this is shaped by factors other than the bank's intentions with regard to policy. Central banks typically have large staffs devoted to collecting and analyzing information about current conditions in the economy, as an input into policy deliberations; and the accuracy of private-sector understanding of the state of the economy might be improved if the central bank were to reveal more about what it believes it has learned. A second topic is the content of the policy decisions that are made in the central bank about current operating targets. For example, as noted in the introduction, the Fed did not publicly confirm the existence of an operating target for the federal funds rate prior to 1994, whereas current practice is to release a statement immediately following each meeting of the FOMC, which, among other things, 
announces the operating target agreed upon at that meeting. A third possible kind of communication would be a description (which might be more or less explicit) of the strategy that guides the central bank's policy decisions in general. A fourth type of communication, much debated in the U.S. at present, makes statements about the outlook for future policy, in light of the current situation, without necessarily asserting that this illustrates a general rule that will always be followed.

These are all types of communication in which the public might be interested, and a general commitment to increased "transparency" might be taken to require greater explicitness about all of these matters. But the way in which " transparency" about one or another of these matters relates to the goal of more effective stabilization policy is somewhat different in each case. The first two types of communication are the ones that are least controversial among central bankers; ${ }^{6}$ to the extent that there are doubts about the desirability of saying more about the central bank's analysis of current conditions, for example, this is largely connected to the way that the public may use this information to make inferences (rightly or wrongly) about the bank's intentions regarding future policy. And it is in any event the effect of central-bank talk on the public's expectations regarding future policy that is critical for the concerns introduced above. Hence it is communication about the way in which policy should be conducted in the future (the third and fourth types of communication listed above) about which I wish to speak here.

One might, first of all, make statements about the targets or objectives that future policy decisions will aim to achieve; ideally, one might imagine a full description of a policy rule to which the policy committee intends to conform. This is the ideal suggested by the theoretical literature, on the basis of the considerations summarized above. On the one hand, private-sector decisions depend, in principle, not just on near-term expectations, but on the expected state-contingent evolution of the economy far into the future, and not just on what is most likely to happen, but on how the economy will evolve under all possible future contingencies; and one could only hope to communicate about what should happen in all of the relevant future states through a discussion of the bank's general strategy. Moreover, an optimal policy requires that the central bank commit itself to behave in a different way than would correspond to discretionary optimization. It is difficult to imagine institutionalizing such conduct other than through a conscious commitment to a particular strategy inside the

\footnotetext{
${ }^{6}$ Note, however, some qualifications to this in section 1.3 below.
} 
central bank itself; and if such a conscious intention exists, a public statement of the commitment is likely to help the policy committee to remember its intention.

But what does any of this have to do with communication policy? The public commitment of a central bank to particular targets or to a particular policy rule will not be matters for routine, ongoing communication with the public that requires institutionalization. It is true that from time to time it will be appropriate to change the targets - as, for example, in the case of the change in the U.K. announced in December 2003, from an RPIX target of 2.5 percent per annum to a CPI target of 2.0 percent - but announcements of this kind are not what is generally understood by "communication policy." Would communication policy be important, then, for a central bank that was actually able to commit itself to a sensible policy strategy?

There are two reasons why it surely would be. The first is the need for verifiability of the central bank's commitment. One might imagine that the central bank's seriousness about its declared targets could be ensured by checking whether they are met, without requiring the bank to say anything about how it ensures that they are met. For example, under a rumor that was widespread at one time, accountability was ensured in New Zealand by a "contract" with the Governor of the RBNZ according to which the Governor could be fired if realized inflation ever went outside a certain band. In practice, however, it makes more sense to monitor the existence of good-faith efforts to achieve the bank's targets than to suppose that one can demand that the targets will actually be fulfilled at all times; and this will require communication by the central bank about the rationale for its policy decisions. Moreover, to the extent that optimal target criteria involve the expected paths of variables that cannot yet be directly measured, as is typically the case, it is appropriate to check, not whether the actually realized values satisfy the target criterion, but whether it would have been reasonable for the central bank to expect them to satisfy the criterion at the time of its policy decision. This requires the central bank to discuss the projections on the basis of which the policy decision was made.

The second reason is that in practice, the strategy that a sensible central bank follows (and may wish to be understood to follow) will be too complex to explain through any one-time official statement of its "policy rule." On the one hand, the set of contingencies that may arise (and matter substantially for policy if they do) are extremely various. As a consequence, an explicit rule of conduct (one specific enough to indicate unambiguously the instrument setting appropriate to any given 
circumstances) would either contain too many provisos to actually be written down, or would deal in a grossly inadequate way with the situations actually encountered with some frequency. ${ }^{7}$ Moreover, as Bank of England Governor Mervyn King (2005b) has stressed in his recent Mais Lecture, the central bank's understanding of the monetary transmission mechanism will surely continue to evolve; but this means that an explicit rule that was judged to be optimal on the basis of the bank's preferred model of the economy in one year would surely no longer be judged optimal from the point of view of the bank's best understanding a few years later. ${ }^{8}$

These considerations are sometimes taken to imply that the very idea of advance commitment to a policy strategy is impractical, and that the only sound approach will be something close to pure discretion. I do not believe so; nor is that the point of Governor King's discussion. What they do imply, however, is that in practice, the kind of commitment that it is sensible for a central bank to make in advance, and the kind that it is sensible for it to try to explain to the public, is a commitment to a general strategy, with the implications of this strategy for the precise instrument settings that will be appropriate under particular circumstances left to be determined when it is known which circumstances have arisen. Similarly, the general strategy should be one to which the bank can expect to adhere even as its views about the details of the monetary transmission mechanism change, though its current best guess about those details will play an important role in deliberations about the particular actions that will best implement the general strategy.

The general strategy to which the bank commits itself nonetheless can and should be more specific than a mere promise to do "whatever best serves social welfare" in whatever circumstances have arisen, and it should require a different approach to policy than the one that would be chosen by a discretionary optimizer. For example, it should bring about a lower average rate of inflation than would result (according to most plausible economic models) from discretionary optimization; and it should require departures of the inflation rate from that long-run average to be less persistent on average than would most likely result from discretionary optimization as well. ${ }^{9}$

\footnotetext{
${ }^{7}$ The point here is that while any one "special" situation with which the rule does not deal might be highly unlikely ex ante, the central bank would likely face some such situation quite often, as the number of possible "special" situations is so large.

${ }^{8}$ Charles Goodhart has also stressed (in private communication) that a monetary policy committee's views will inevitably change over time with changes in the composition of the committee.

${ }^{9}$ It should also allow policy to be history-dependent in a way that discretionary optimization is
} 
And in order for the benefits of these aspects of the bank's strategy to be obtained, the consequences of this commitment for the economy's likely future evolution must be made clear to the public, at least to the extent that this is possible given the uncertainty faced by the central bank itself.

Because the way in which the strategy will be implemented in practice cannot be reduced to an explicit instrument rule, ongoing communication on the part of the central bank can play an important role in clarifying the consequences of the general strategy. It can be very useful to illustrate the consequences of the bank's approach to policy deliberations by showing how the particular situations that have already arisen were analyzed; over time, the observation of a sufficient number of such cases should help the private sector to some degree of understanding of the central bank's "reaction function." (The chances of this occurring, of course, are vastly greater in the case that the bank does itself seek to base its decisions on a stable set of principles, despite the varying kinds of information that are considered on different occasions, and in the case that it explains its decisions each time by reference to those same principles.) But this approach to making public the systematic character of policy will depend on a commitment to frequent communication about ongoing policy deliberations within the bank. Ideally, such communication will be regular, detailed, and structured, as in the case of the Inflation Reports of the inflation-forecast targeting central banks (discussed further in section 3).

A somewhat different way in which central-bank talk can convey information about future policy is through direct statements about the current outlook for policy. Such statements - illustrated by the comments that have recently been included in the post-meeting statements of the FOMC in the U.S. (discussed further in section 2) - fall considerably short of stating a general rule for the conduct of policy, and are likely to refer only to future policy over a fairly short horizon. They can, however, be much more specific about matters such as how the policy instrument will be set than descriptions of the bank's general strategy are likely to be.

There are a number of reasons why this kind of communication can also be useful. First of all, it might be used to some extent as a substitute for communication about a general strategy, for those central banks that are reluctant to commit themselves to any target or strategy in general, but may nonetheless be willing to commit themselves occasionally to an ad hoc departure from fully discretionary policy. In fact, not; this is discussed further below. 
communication of this kind has been used most notably thus far by central banks such as the U.S. Federal Reserve and the Bank of Japan, ${ }^{10}$ which have not been willing to explicit themselves to quantitative inflation targets.

But discussion of the outlook for policy is likely to play a useful role even in the case of a bank that is as explicit about its general commitments as it is likely to be possible for any bank to be. As just discussed, in practice it would not be possible for a bank to commit itself to an explicit instrument rule. There would thus be considerable room to give further information about the likely path of the policy instrument on particular occasions, that would neither contradict nor be made unnecessary by the bank's commitment to its general strategy. Such communication would help to flesh out the concrete implications of the general strategy, and increase the ability of the private sector to make correct inferences about the consequences of the bank's commitments for the future evolution of the economy. This kind of amplification of the general strategy is likely to be especially useful when unusual circumstances arise, so that the implications of the strategy for circumstances of that kind might not be at all apparent simply from observation of the bank's past behavior. The situation discussed in the next section - where the Federal Reserve found itself at least potentially constrained by the zero lower bound on nominal interest rates, though this constraint had been irrelevant for more than fifty years - provides a good example of such an occasion.

A further argument for the desirability of communication about the outlook for future policy - and one in no way tied to unusual circumstances - follows from the history-dependence of an optimal policy commitment. Optimal policy requires not only that the central bank commit itself to a particular rule of conduct, but that the rule be history-dependent: it must take account of past conditions, even some that no longer matter for an evaluation of what it would be possible to achieve from now on. Hence any institutionalization of an optimal rule must involve keeping some record of past conditions. It is furthermore worth noting that what matters is not what the past was actually like (as viewed from the future, when the history-dependent policy action is to be taken), but how matters appeared then, as this is what would determine the value at the earlier time of being able to shift expectations regarding

\footnotetext{
${ }^{10}$ I discuss recent policy signaling by the Fed in section 2. On recent policy signaling by the Bank of Japan, see Bernanke et al. (2004), Fujiki and Shiratsuka (2002), Iwamura et al. (2004) and Oda and Ueda (2005).
} 
future policy. ${ }^{11}$ Thus implementation of an optimal policy requires that a record be kept of how matters appeared to the policy committee in the past, and that those past views condition the later policy decision. And while history-dependent policy requires only that there exist an internal record, the benefits of history-dependence depend on its being understood by the public; this makes a public statement about the aspects of the current situation that should change future policy deliberations appropriate.

There are various ways in which the relevant aspects of past deliberations might be encoded, and in which those records might be used in subsequent deliberations. But one fairly straightforward one - which would make it especially easy for the public to understand the consequences for future policy - would be to indicate at the earlier date the future policy that should be expected to be implemented later, in the absence of developments unforeseen at that time. The policy committee would then be committed to actually implement the policy announced earlier, unless circumstances changed in ways not previously foreseen. Deciding policy in advance (to this extent) would be an obvious way of allowing the policy committee to internalize the effects of anticipations of its later policy, and making public the committee's forecast of future policy would be an obvious way of making clear the expectations regarding future policy that should follow from the intention to make policy history-dependent. Of course, in order to prevent such an advance commitment from implying a nonstate-contingent (and hence suboptimal) rule of conduct, it would be important to specify the assumptions regarding economic developments under which the forecast about future policy had been made, so that the nature of the contingency of the commitment would be clear.

\subsection{Can a Central Bank Talk Too Much?}

There are nonetheless a number of questions that may be raised about the desirability of central-bank communication, especially in the case of communication about future policy intentions. One point of view - once fairly common among central bankers,

\footnotetext{
${ }^{11}$ In optimal policy calculations like the ones discussed in the next section, the history-dependence of optimal policy results from the presence of lagged Lagrange multipliers in the first-order conditions that characterize the optimal state-contingent evolution of the economy. The lagged values of these Lagrange multipliers depend on the decision problem faced by the central bank at its last decision point. For further discussion, see Woodford (2003, chap. 7) and Svensson and Woodford (2005).
} 
though less common now - would question whether it is actually desirable to increase the degree of precision with which the markets are able to anticipate the actions of the central bank, arguing that market interventions by the central bank will be more effective to the extent that the bank is able to surprise the markets. The idea, essentially, is that unanticipated trading by the central bank should move market rates by more, owing to the imperfect liquidity of the markets. Instead, if traders are widely able to anticipate the central bank's trades in advance, a larger number of counter-parties should be available to trade with the bank, so that a smaller change in the market price will be required in order for the market to absorb a given change in the supply of a particular instrument.

But such an analysis assumes that the central bank better achieves its objectives by being able to move market yields more, even if it does so by exploiting temporary illiquidity of the markets. Yet the temporarily greater movement in market prices that is so obtained - if any greater movement is obtained ${ }^{12}$ — occurs only because these prices are temporarily less well coupled to decisions being made outside the financial markets. Hence it is not at all obvious that any actual increase in the effect of the central bank's action upon the economy - upon the things that are actually relevant to the bank's stabilization goals - can be purchased in this way. ${ }^{13}$

Another ground for caution about the amount that the central bank should say about its view of the future is provided by the analysis of Morris and Shin (2002) of the possible disadvantages of public information provision. Morris and Shin consider a stylized game in which individual market participants each choose an action on the basis of their observation of both a public signal (common knowledge to all market participants) and a private signal. Both the public signal and the private signal are noisy measures of some payoff-relevant "fundamental" state variable; each market

\footnotetext{
${ }^{12}$ Demiralp and Jorda (2002) find that it has been possible for the Fed to move the funds rate with a smaller quantity of open-market operations since 1994 than before, and interpret this as an effect of the FOMC's greater transparency about its funds rate target since 1994. This would suggest that advance signaling of what the Fed wishes to achieve makes it easier for the Fed to move interest rates where it wishes them to be, contrary to the argument mentioned in the previous paragraph. There is a simple reason why this is likely to be the case, namely, intertemporal substitution in the demand for federal funds as a result of the fact that reserve requirements require only a certain average level of reserves over a two-week maintenance period.

${ }^{13}$ I develop this point in more detail in Woodford (2001), where a simple model of policy effectiveness with incomplete market participation is presented.
} 
participant is assumed to care both about choosing an action that is appropriate given the fundamental state of the economy, and about choosing an action that is not too different from others' actions. (The latter aspect of the assumed payoffs in the game gives it some of the characteristics of Keynes' famous "beauty contest".) Morris and Shin show that while an increase in the precision of the private information available to market participants necessarily increases social welfare, an increase in the precision of the public signal has an ambiguous effect on welfare. On the one hand, it will increase the accuracy of each market participant's assessment of the current state of the economy, with the result that equilibrium actions are on average more appropriate to current fundamentals. But on the other hand, it will reduce the weight that each market participant puts on her private information in forming her estimate of current conditions and hence in choosing her action, and increase the weight placed on the public signal instead. This second effect makes the average action less appropriate to the current state, because the error in the public signal affects everyone's action (while the errors in participants' private signals instead cancel out, and have no effect on the average action). It is possible for the second effect to outweigh the first, so that welfare is reduced by an increase in the precision of the public signal - that is, by an increase in the amount of information conveyed by it. ${ }^{14}$

Morris and Shin stress that a leading application of their analysis should be to the question whether increased transparency on the part of a central bank is necessarily a good thing, ${ }^{15}$ and their argument has received a great deal of attention in central banks and in the financial press ${ }^{16}$ often in the context of discussions of the desirability of the kind of signaling of future policy described in section 2 of this paper. However, the applicability of their analysis to this kind of central-bank communication is far from obvious.

\footnotetext{
${ }^{14}$ The decision to release more information is represented in the Morris-Shin model by the release of a signal that is a less noisy measure of the fundamental state. Their conclusion that under some circumstances it may be better for a central bank to say less is in fact a finding that under certain circumstances it would increase social welfare for the central bank to release estimates of the state of the economy that contain more random noise. Stating the conclusion this way would make it seem more paradoxical; but this is actually what their formal analysis implies.

${ }^{15}$ The application of the Morris-Shin insight to the issue of the desirable amount of central-bank communication is developed especially in Amato, Morris and Shin (2002) and Amato and Shin (2003).

${ }^{16}$ See, for example, the discussion in the Economist (2004), and by Kohn (2005) and Issing (2005).
} 
It is important to recognize that while Morris and Shin show that a (small) increase in the precision of the information released by a public authority can be welfarereducing under some circumstances, the conditions under which this result is obtained are quite special. First of all, the perverse outcome requires that the central bank's announcement not be too accurate as an indicator of the "fundamental" in question, while market participants' private information about that same state variable must be sufficiently precise. In fact, as Svensson (2005) points out, in the Morris-Shin model the precision of each participant's private information must be at least 8 times as great as the precision of the public signal in order for the perverse outcome to be possible. ${ }^{17}$ And it is not obvious that private information should be so much superior to the information that would be revealed by a central bank that makes an effort to tell what it knows.

Of course, central banks are themselves less than omniscient, and one argument within central banks for limiting the amount that is said to the public is the straightforward observation that the central bank does not know the answers to all of the questions about which market participants would wish to be informed. But the Morris-Shin result requires not only that the central bank's assessment of the fundamental, should it choose to reveal it, would not be God's truth; it requires that it be much less accurate on average than the estimate that any market participant would make on her own, in the absence of comment by the central bank. Even in the case of an assessment of economic conditions that are largely outside the control of the central bank, it is not plausible that a central bank's guess should be this bad. For example, Romer and Romer (2000) find that Federal Reserve Board staff forecasts compare favorably with the accuracy of even the most sophisticated private forecasters' forecasts, and this is hardly surprising given the size of the Fed staff and its privileged access to certain kinds of information.

And the assumption about relative accuracy required for a perverse result is least plausible of all in the case of central-bank communication about likely future policy. If there is one issue about which a central bank should have better information than that of market participants, it is the bank's own deliberations about matters (such as the path of the federal funds rate) that are essentially under its direct control. ${ }^{18}$

\footnotetext{
${ }^{17}$ The minimum required ratio depends on the parameter $r$ of the loss function (1.1) below, but it is always 8 or higher; see the Appendix for details.

${ }^{18}$ Governor Kohn (2005) suggests that the danger identified by Morris and Shin applies even more
} 
Again, it is often objected that even if the federal funds rate is completely subject to decision by the FOMC, this does not mean that the FOMC already knows what it will decide about where it will want the funds rate to be next year; and it is suggested that an inaccurate forecast may be worse than none at all. But even if the Committee does not yet know the precise answer to questions such as when the current series of quarter-point increases in the funds rate target will end, it surely is in a better position than outsiders to make an informed guess. It is therefore implausible that a public revelation of its best guess about this matter could reduce welfare on the grounds proposed by Morris and Shin.

A second requirement for the perverse result in the Morris-Shin model is that the game played by market participants must have elements of a "beauty contest". Market participants must care, not just about acting in a way that conforms as much as possible with current fundamentals, but also about acting similarly to the way that others do; and they must care sufficiently strongly about conformity relative to their concern with fundamentals. Specifically, Morris and Shin assume a game in which each player $i$ wishes to minimize the expected value of a loss function

$$
L^{i} \equiv(1-r)\left(a_{i}-\theta\right)^{2}+r E_{j}\left(a_{j}-a_{i}\right)^{2}
$$

where $a_{j}$ is the action of a generic player $j, \theta$ is the unknown value of the "fundamental" state, $E_{j}$ denotes an average over the continuum of players indexed by $j$, and $0<r<1$ is the relative weight on the conformity objective. The possibility of a perverse result requires not only the presence of the second term in the loss function, but that $r>1 / 2$, so that the weight on the second term is greater than the weight on the first; if $r \leq 1 / 2$, then an increase in the precision of the public signal raises welfare regardless of what one may assume about the relative precisions of the public and private signals.

But again it is not obvious that one should assume that this is the relevant case where signals regarding the future path of interest rates are concerned. Is it really true that, holding constant a bond trader's estimate of the "fundamental" value of a

in the case of communication about the "policy inclination" than communication about the economic outlook, because markets are especially likely to pay great attention to what a central bank says about future policy. But in the model of Morris and Shin, market participants put greater weight on the public signal the greater the expected relative precision of that signal (i.e., the greater the extent to which the public authority is believed to be relatively better informed), but the more this is true the stronger will be the relative strength of the desirable effect of increased transparency. 
bond (based on both the central bank's hints about the future path of interest rates and his own information), the fact that other traders currently wish to buy the bond would make him wish to buy more of it? Might the second piece of information not instead make him think it is a good time to sell the bond that is overvalued on average, perhaps because average opinion has been influenced by views of the central bank that he disagrees with? If so, then the game among market participants would be characterized by "strategic substitutability" rather than "strategic complementarity," and, as Morris and Shin note in their article, the informational-externality argument would instead imply that market participants will put less weight on the public signal than would be socially optimal, rather than paying too much attention to the central bank's announcements.

Finally, the perverse result is possible in the model of Morris and Shin only because of a particular assumption about the proper measure of social welfare, that in fact is highly debatable. Recall that individual market participants are assumed to care about two distinct objectives - acting in a way that is appropriate given the fundamental state, and acting in the same way that others act - represented by the two terms in the loss function (1.1). But Morris and Shin rank alternative equilibria using a welfare criterion that reflects only one of these private objectives; they assume that public policy should seek to minimize a social loss function

$$
L^{s o c, M S} \equiv E_{i}\left[\left(a_{i}-\theta\right)^{2}\right]
$$

the average squared distance of individual actions from the one that would be appropriate given the fundamental state $\theta$. While individuals are assumed to dislike taking an action that differs from the actions taken by others, there is assumed to be no social welfare consequence of less coordination across the actions taken by different market participants.

It is not obvious, however, that this makes sense. The same factors that make individuals seek to avoid actions that are too far out of line with the actions of others may well imply that there are social losses from such lack of coordination. And the simplifying assumption made in the example of Morris and Shin is not innocuous. For the factor that they omit from their consideration of social welfare is one that necessarily favors greater precision of the public signal. An increase in the precision of the public signal will necessarily reduce the dispersion of individual market participants' actions, exactly because it leads them to put less weight on their 
private information, which is the source of dispersion.

I show in the Appendix that if one were instead to rank outcomes on the basis of a social loss function proportional to $E_{i}\left[L^{i}\right]$ — that is, by the population average of the individual loss function (1.1) - then this alternative social loss function is necessarily reduced by increasing the precision of the public signal, even though the Morris-Shin loss function $L^{s o c, M S}$ may be increased. As noted above, the only case in which (1.1) can be increased is when $r$ is large; but this is exactly the case in which the goal of reducing the dispersion of opinion becomes the more important factor for social welfare, under the alternative proposed here. Since the objective proposed here seems the more reasonable one, I find little reason to be troubled by the Morris-Shin example, even when one grants the parametric assumptions required for their perverse case. ${ }^{19}$

Of course, central bankers may have other reasons to be concerned about saying too much about matters about which they are themselves uncertain. One of the reasons most often cited is a concern that members of the public could be harmed by reliance on bad information supplied by the central bank. But this would not be a concern if the central bank's audience could be assumed to consist of rational maximizers who optimally use the information available to them, as in the model of Morris and Shin. ${ }^{20}$ And even granting that not all market participants can be relied upon to be quite this sophisticated in the way that they respond to news, it is not obvious that one should expect them to make fewer mistakes if left to puzzle things out for themselves. The fact that people are not ideal information processors means that a central bank should give thought to the question of what market participants most need to know and how best to express what it is trying to tell them; thus it needs to have a communication strategy, and not simply a concern for "transparency" in

\footnotetext{
${ }^{19}$ Roca (2005) obtains a similar result in the case of a model of price-setting under monopolistic competition of the kind discussed by Amato and Shin (2003), when a welfare objective is used that is based on the preferences of the households in the model. Hellwig (2004) similarly finds that transparency is welfare-increasing in an explicit model of complementarities in price-setting, while Angeletos and Pavan (2004) obtain a similar conclusion in a model of complementarities in investment.

${ }^{20}$ In the model of Morris and Shin, no individual is harmed by her observation of the public signal; if she were, she could choose to ignore it. Each market participant conditions her action on the public signal to precisely the extent that minimizes her expected losses, taking into account the likely error in the available sources of information.
} 
the sense of letting anyone see whatever they wish. But it is not a reason for central banks not to try to increase the amount that is effectively communicated.

I do not wish to minimize the difficulties associated with effective communication with the public, especially about matters as subtle as the likely conduct of policy under future circumstances that are not yet known. In practice, communication strategies improve only through a process of trial and error, even when central banks give considerable attention to the problem of how to tell the public more; for market participants must learn to interpret what the central bank is saying, and the central bank must learn to anticipate how its statements will be interpreted. The remaining sections of this paper consider two recent case studies in which central banks have grappled with the question of how to talk about the outlook for future monetary policy.

\section{Signaling Future Policy Near the Interest-Rate Lower Bound}

A case in which the benefits of being able to steer expectations regarding the future conduct of policy, other than through current policy actions alone, are especially clear is in the case in which overnight interest rates are already as low as it is possible or desirable to make them, while underutilization of productive capacity and/or unduly low inflation continue to suggest a need for further monetary stimulus. Japan, where the overnight rate (call rate) has been at zero almost continuously since 1999, yet deflation continues, provides an obvious example of the possibility of such a situation. But the U.S. faced a similar situation, or at least the risk of one, in the spring and summer of 2003, as the federal funds rate operating target was reduced to only one percent, while the strength of the recovery remained doubtful and inflation remained lower than the Fed was entirely comfortable with.

Does monetary policy become impotent when the zero lower bound is reached, as classic analyses of the possibility of a "liquidity trap" in static models would suggest? Eggertsson and Woodford (2003) show that the answer is yes, in the context of an explicit general-equilibrium model of the transactions demand for money with sticky prices, if monetary policy is understood to consist solely of various ways in which the monetary base might be expanded through current open-market operations, without 
any change in the way in which monetary policy is expected to be conducted in the future. ${ }^{21}$ But they also show that changes in the expected conduct of monetary policy in the future - after real conditions change, so that the policy that would be preferred at the time, but for the need to fulfill earlier commitments, would be one in which nominal interest rates would be well above zero - can have a very substantial effect on inflation and real activity during the period in which the zero bound is a binding constraint. This indicates the possibility of substantial benefits from signaling that future policy will be conducted in a different way than might otherwise have been expected, simply as a result of the economy's having been temporarily constrained by the interest-rate lower bound.

\subsection{An Optimal Policy Commitment when the Lower Bound Binds}

It is worth recapitulating some of the details of the analysis of optimal policy by Eggertsson and Woodford (2003), as a basis for discussion of the recent use of communications policy in both the U.S. and Japan. The exposition is simplest if we proceed directly to a log-linear approximation to their intertemporal equilibrium model with Calvo-style staggered price-setting. In this approximation (which, except for the imposition of the zero bound, is identical to the one used in studies such as Clarida et al., 1999), inflation $\pi_{t}$ and the output gap $x_{t}$ are determined by a pair of equations each period, ${ }^{22}$

$$
\begin{gathered}
\pi_{t}=\kappa x_{t}+\beta E_{t} \pi_{t+1}, \\
x_{t}=E_{t} x_{t+1}-\sigma\left[i_{t}-E_{t} \pi_{t+1}-r_{t}^{n}\right],
\end{gathered}
$$

where $\kappa, \sigma$ are positive coefficients, and $0<\beta<1$ is the utility discount factor, $i_{t}$ is the riskless short-term (one-period) nominal interest rate, and $r_{t}^{n}$ is the natural (real)

\footnotetext{
${ }^{21}$ This analysis extends the discussion of Krugman (1998) to include a more developed treatment of the dynamics of price adjustment, the connection between interest-rate policy and the generation of inflationary expectations, and the consequences of alternative forms of open-market operations.

${ }^{22}$ Equation (2.1) is here written without the "cost-push shock" term that plays a central role in the analysis of optimal policy in Clarida et al. The issue with which we are here concerned (the possible difficulties for policy created by the zero bound) is not one for which the existence of a "cost-push" term is important, whereas the existence of fluctuations in the natural rate of interest $r_{t}^{n}$ is instead critical. The optimal policy rule derived by Eggertsson and Woodford (2003), however, is also optimal in the presence of "cost-push shocks" of the kind hypothesized by Clarida et al.
} 
rate of interest, that evolves exogenously as a result of real disturbances. The interest rate $i_{t}$ is assumed to be the instrument of monetary policy, and is here treated as under the direct control of the central bank. We may then suppress the equations of the model involving the demand for base money. However, it is important to note that the interest rate will satisfy

$$
i_{t} \geq 0
$$

no matter how much base money is supplied; this lower bound is the constraint on policy with which we are here concerned.

Let us suppose that the objective of policy is to minimize a discounted loss function of the form

$$
E_{0} \sum_{t=0}^{\infty} \beta^{t}\left[\pi_{t}^{2}+\lambda x_{t}^{2}\right],
$$

with some weight $\lambda>0$. It follows from equations (2.1) $-(2.2)$ that as long as $r_{t}^{n} \geq 0$ at all times, one possible rational-expectations equilibrium is one in which inflation and the output gap are both zero at all times, and in such a case, this is obviously the equilibrium that minimizes the loss function (2.4), and so is optimal. But it is possible for real disturbances to cause the natural rate of interest to be temporarily negative. ${ }^{23}$ In such a case, the zero-inflation equilibrium is no longer a possibility. (Note that this equilibrium requires that $i_{t}=r_{t}^{n}$ at all times, so that (2.3) is satisfied only if $r_{t}^{n} \geq 0$ at all times.)

Given that the pursuit of zero inflation at all times would be optimal in the event that the lower bound on interest rates were never a problem, one might suppose that even given the possibility of an occasionally binding lower bound, it would be optimal to pursue zero inflation at all times, if the interest-rate lower bound allows it. But this is not true. As an illustration, consider the particular kind of real disturbance analyzed in the numerical example of Eggertsson and Woodford. The "normal" (longrun average) level for the natural rate of interest is $\bar{r} \equiv \beta^{-1}-1>0$. However, at some date, an unexpected disturbance temporarily lowers the natural rate to a level $\underline{r}<0$. There is then a probability $0<p<1$ each period that "fundamentals" revert to their normal state, so that $r_{t}^{n}=\bar{r}$ again, and in this case, the natural rate of interest is expected to equal $\bar{r}$ indefinitely (there are no further disturbances). With

\footnotetext{
${ }^{23}$ This is Krugman's (1998) analysis of the situation of the Japanese economy since the mid-1990s. See also Woodford (2003, chap. 4) for discussion of some of the kinds of real factors that can shift the natural rate of interest.
} 
probability $1-p$, instead, the low-natural-rate state will continue in the following period, conditional on the natural rate remaining at $\underline{r}$ in the current period.

In this case, under the hypothesized policy, the central bank will achieve zero inflation from period $T$ onward, where $T$ is the random date at which fundamentals revert to their normal state. This will be associated with a constant output gap of zero, and a constant nominal interest rate equal to $\bar{r}>0$. Prior to this date, inflation will equal the same rate $\underline{\pi}$ each period, the output gap will equal the same value $\underline{x}$, and the nominal interest rate will equal the same value $\underline{i},{ }^{24}$ where these constant values satisfy

$$
\begin{gathered}
\underline{\pi}=\kappa \underline{x}+\beta(1-p) \underline{\pi}, \\
\underline{x}=(1-p) \underline{x}+\sigma[\underline{r}+(1-p) \underline{\pi}-\underline{i}],
\end{gathered}
$$

as a result of equations $(2.1)-(2.2)$, together with the requirements that

$$
\underline{\pi} \leq 0, \quad \underline{i} \geq 0
$$

and that at least one of the inequalities in (2.7) must hold with equality. (The central bank achieves the zero inflation target at dates prior to $T$, unless the zero bound prevents the inflation rate from being raised to zero.)

An equilibrium of this form exists as long as

$$
(1-p)\left(\beta+\frac{\kappa \sigma}{p}\right)<1
$$

i.e., as long as the degree of persistence of the disturbance is not too great. One can easily show that under the assumption that $\underline{r}<0$, it is the lower bound on interest rates that is binding in (2.7), and the solution is given by

$$
\underline{\pi}=\frac{\underline{r}}{(\kappa \sigma)^{-1} p[1-\beta(1-p)]-(1-p)}<0, \quad \underline{x}=\frac{1-\beta(1-p)}{\kappa} \underline{\pi}<0,
$$

together with $\underline{i}=0$. Thus deflation and output below the natural rate continue for as long as the disturbance to fundamentals does; even if prices are revised fairly often on average, the binding lower bound on interest rates can result in a slump that lasts for years. Furthermore, (2.9) implies that even a very mildly negative value for

\footnotetext{
${ }^{24}$ Here I restrict attention to the Markovian (minimum-state-variable) equilibrium consistent with the hypothesized policy. Note that when this equilibrium exists, it represents at least one possible outcome, and the fact that it may be very bad indicates the problem with this approach to policy.
} 
the natural rate of interest can result in very severe deflation and contraction of real activity. Note that if the left-hand side of (2.8) is close enough to 1 (and there is no reason why it may not be), the rate of deflation and the size of the negative output gap in (2.9) become arbitrarily large, regardless of the degree to which $\underline{r}$ is less than zero. $^{25}$

The contractionary effects may be quite large, due to a chain of circular causation. A real interest rate above the natural rate (owing to the zero bound) causes a negative output gap and deflation prior to period $T$. The anticipation of these effects, in the contingency that the natural rate continues to be negative in the following period, then depresses demand further and creates even stronger deflation in any period prior to $T$, owing to the effects of expectations $E_{t} \pi_{t+1}<0, E_{t} x_{t+1}<0$ in equations (2.1)(2.2). The anticipation of these even stronger deflationary and contractionary effects causes still greater deflation and contraction, and so on, in a cumulative process that does not even converge unless (2.8) holds.

It is crucial in the above reasoning that the central bank is expected to target zero inflation again as soon as this becomes possible. While this would in fact make sense ex post - and so would be the outcome in a Markov equilibrium with discretionary optimization by the central bank - a better outcome is possible if the central bank commits to behave otherwise once fundamentals revert to their normal state. This can be seen if we repeat the above calculations, but assume that the central bank will bring about an inflation rate $\bar{\pi}>0$ (and an associated output gap $\bar{x}>0$ ) in period $T$. Under this variation on our assumptions, the solution for $\underline{\pi}$ in (2.9) generalizes to $^{26}$

$$
\underline{\pi}=\bar{\pi}+\frac{\underline{r}+\bar{\pi}+p \sigma^{-1}\left[\bar{x}-x^{s s}(\bar{\pi})\right]}{(\kappa \sigma)^{-1} p[1-\beta(1-p)]-(1-p)},
$$

where $x^{s s}(\bar{\pi}) \equiv(1-\beta) \kappa^{-1} \bar{\pi}$ is the steady-state output gap associated with steadystate inflation rate $\bar{\pi}$.

In the case that $\bar{x}$ is increased along with $\bar{\pi}$ to the extent that it would in the case of a permanent commitment to the inflation target $\bar{\pi}$, the multiplier effect of an

\footnotetext{
${ }^{25}$ Of course, for a large enough rate of deflation and departure from the natural rate of output, the local approximations in $(2.1)-(2.2)$ cease to be accurate; but this suffices to show that the departures from the zero-inflation steady state need not be small, for if they were small the local approximations would be valid and equations (2.9) would be approximately correct.

${ }^{26}$ Equation (2.10) applies as long as $\bar{\pi} \leq-\underline{r}$, so that the zero bound continues to bind when $r_{t}^{n}=\underline{r}$.
} 
increase in the long-run inflation target $\bar{\pi}$ on the inflation rate $\bar{\pi}$ during the "liquidity trap" is given by

$$
\frac{\partial \underline{\pi}}{\partial \bar{\pi}}=1+\mu
$$

where $\mu>0$ is the (possibly very large) multiplier $-\partial \underline{\pi} / \partial \underline{r}$ implied by equation (2.9). There is a correspondingly large effect of a commitment to target an inflation rate $\bar{\pi}>0$ on the value of $\underline{x}$ as well. Thus a commitment to a future inflationary policy can mitigate the effects of the zero lower bound, as argued by Krugman (1998). In the forward-looking model of inflation and output determination used here, these effects are quite large, owing to the same chain of circular causation as above, but now operating in the opposite direction (a "virtuous circle").

However, the optimal policy commitment (in order to minimize (2.4) is not a simple commitment to a higher long-run inflation target. The effects just discussed on inflation and output while the zero lower bound binds depend only on $\bar{\pi}$ and $\bar{x}$ being delivered in period $T$, the first period in which the natural rate of interest is again positive; there is no need to commit to continued inflation forever, and this will instead lead to unnecessary distortions in the long run. Eggertsson and Woodford (2003) show that the optimal policy involves a commitment to the creation of a modest inflationary boom in period $T$, and then stabilizing the price level shortly thereafter (i.e., returning to a long-run inflation rate of zero), at a level slightly higher than the one that would have been reached in the absence of the disturbance. ${ }^{27}$

This is illustrated in Figure 1, which shows the paths of the nominal interest rate, the inflation rate, and the output gap under the optimal state-contingent policy commitment (for particular numerical parameter values discussed by Eggertsson and Woodford), in the case that $T$ is exactly 15 quarters after the onset of the real disturbance. The figure also shows the paths of all three variables in the case of a commitment to zero inflation (or discretionary optimization). While the creation of the inflationary boom (by keeping interest rates low for five more quarters, rather than immediately raising them to the level that would be required to achieve price stability immediately at date $T$ ) results in mild distortions after date $T$, these are only temporary (as price stability and a zero output gap are achieved fairly soon),

\footnotetext{
${ }^{27}$ Jung et al. (2005) reach a similar conclusion in the case of different assumed dynamics for the natural rate of interest. Adam and Billi (2003) characterize optimal policy in the same model in the case of continuing stochastic fluctuations in the natural rate that cause the zero bound to bind periodically.
} 
(a) interest rate

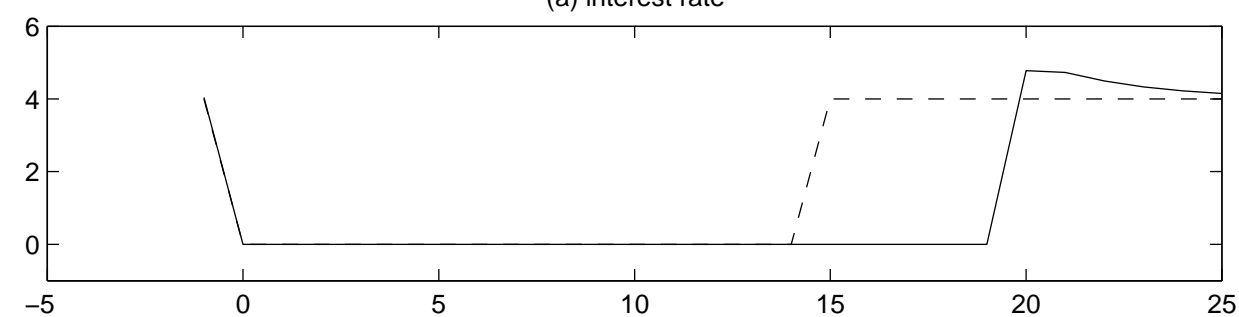

(b) inflation

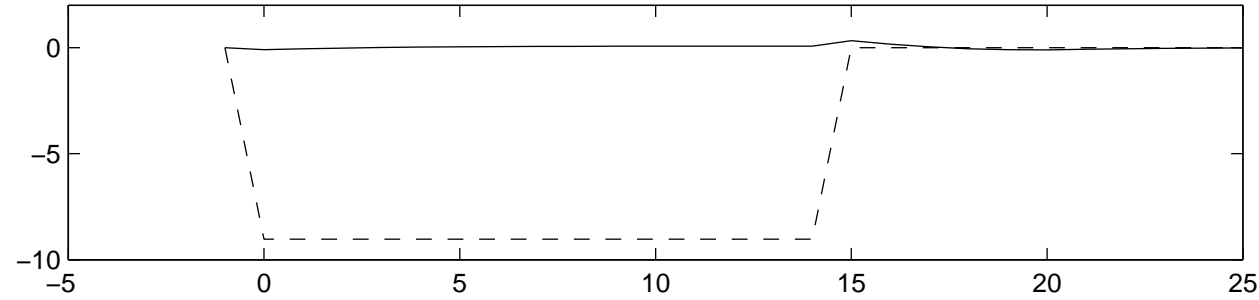

(c) output gap

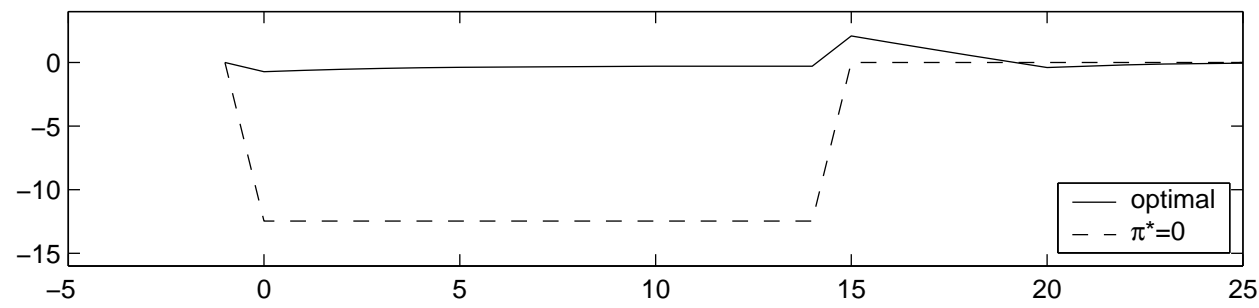

Figure 1: Comparison of state-contingent paths under two alternative monetary policies, in the case that the natural rate of interest is negative for 15 quarters. (Source: Eggertsson and Woodford, 2003)

and are quite mild relative to the size of the distortions prior to date $T$ that are thereby avoided. The strong effect of the commitment to subsequent reflation of the economy occurs because of the chain of circular causation just discussed. ${ }^{28}$

This numerical example illustrates several points of more general importance. First, it shows how a credible commitment regarding the future conduct of policy can, at least in principle, greatly expand a central bank's ability to achieve its stabilization objectives. But in addition, it shows that the an optimal commitment requires not only that the central bank pledge to behave in a different way than would a dis-

\footnotetext{
${ }^{28}$ These effects are quite strong because it is assumed in the example that there is only a ten percent chance each quarter that fundamentals will revert to the normal state. Thus at any point in time while the natural rate of interest is negative, it is expected that this situation is likely to persist for two or more additional years.
} 
cretionary optimizer; the conduct of policy must also be history-dependent. For the inflation rate that should be targeted once the natural rate of interest is positive is not the one that the central bank always targets in the case of fundamentals of that kind; rather, the central bank should temporarily behave differently because of what the economy's situation has been in the recent past, even though those circumstances no longer affect what it would be possible for policy to achieve from now on. As I have discussed above, this history-dependence of the optimal policy commitment strengthens the case for explicit discussion by the central bank of the way in which current conditions change the outlook for future policy. If it were desired simply to always target an inflation rate $\bar{\pi}>0$, then it might not be necessary for the central bank to talk about this while in the liquidity trap; one might suppose that the central bank's long-run inflation target would already have been learned by the private sector from its previous behavior, and that people might confidently expect the central bank to return to the pursuit of this target once circumstances allowed it to be achieved, without any need for comment to that effect. But if it is desired that the public understand, while policy is constrained by the zero bound, that future policy will be different from what it usually is under similar circumstances, because of the current difficulties, then it is reasonable to suppose that the central bank may need to discuss this, rather than expecting this to be obvious from past experience. The case will be even stronger if the circumstances under which the zero bound becomes a constraint are fairly unusual.

It is also worth noting that the advantages of commitment to a history-dependent future policy do not depend on reaching the zero bound. It is simply important that there be some lower bound on the level of short-term nominal interest rates that the central bank is willing to target; none of the analysis just sketched depends on there being satiation in money balances when this bound is reached. In the analysis of Eggertsson and Woodford, there is no need for history-dependent policy unless there is some state in which the zero bound binds; but that is because they assume there is no other obstacle to lowering interest rates. If (as was arguably the case for the Fed in 2003) there is a positive level of interest rates $i^{l}$ below which the central bank does not wish to go, a similar analysis applies in the case of this lower bound, except that now history-dependent policy becomes valuable if the natural rate of interest ever drops below $i^{l}$, which is even more likely to occur if $i^{l}$ is positive. ${ }^{29}$ Regardless of where the

\footnotetext{
${ }^{29}$ The analysis can similarly be generalized to the case of an objective function in which the
} 
lower bound lies, a commitment to lower interest rates later can substitute, at least partially, for being able to lower interest rates immediately, so that history-dependent policy can relax the constraint implied by the lower bound.

\subsection{Policy Signaling in Practice}

The situation faced by the U.S. Federal Reserve in the summer of 2003 was arguably of the sort contemplated in the above analysis (though the model used in the calculations is obviously an extreme over-simplification). The federal funds rate operating target had been reduced to 1.0 percent by June of that year, and (at least according to speculation in financial markets and in the press) the FOMC may have been reluctant to move lower than that. Nonetheless, inflation remained low; according to the minutes of the August 2003 meeting of the FOMC, inflation was "already near the low end of what some members regarded as an acceptable range," and "a number of members expressed the view that some further disinflation was probable over the year ahead." While the committee was at least guardedly optimistic about real growth over the next year, it was believed that a substantial period of growth faster than the economy's potential growth rate would be needed to close "the economy's currently wide output gap."

Because of the risk of undesired further declines in inflation - that posed a particular risk insofar as once inflation expectations also fell, the level of real interest rates associated with the nominal interest rate floor would become an even higher one - the FOMC did not wish to tighten policy, despite the improving outlook for real activity. In this regard, it was not judged to be enough that they leave the funds rate target at one percent; for, as explained in section 1, it is primarily the expected future path of the funds rate (and other short rates tied fairly closely to it) that affects spending and pricing decisions, rather than the current level of the funds rate. And there was concern that the public's expectations regarding the future path of interest rates could move sharply upward as news about the real economy improved, because of the way in which the FOMC had typically responded to improvements in real activity in the past (as described, for example, by the "Taylor rule"). These

optimal inflation rate is assumed to be some positive inflation rate $\pi^{*}$, rather than zero. In this case, history-dependent policy is needed only if the natural rate of interest sometimes falls below the level $i^{l}-\pi^{*}$. 
expectations, if allowed to respond in that apparently reasonable way, might slow the recovery of real activity and plunge the U.S. economy into deflation.

The minutes of the August meeting indicate the committee's concern with the recent evolution of market expectations, as indicated by long-term bond yields. The minutes discuss the "dramatic" increase in the ten-year Treasury yield in particular that had occurred in July (see Figure 2, below). "The increase appeared to be based on a number of factors, including investors' interpretation of the Chairman's congressional testimony, the release of Committee members' relatively bullish economic projections, and incoming news regarding the economy and corporate earnings that was seen as signaling a more likely upturn in economic growth," as a result of which the markets were evidently anticipating that increases in the funds rate might come as early as the fall. While the minutes do not clearly identify the reason for the FOMC's decision to introduce an explicit comment on the likely nature of future policy into its post-meeting statement on this occasion, it seems likely that their concern with movements in long-term bond yields on the basis of speculation about their future policy decisions was an important element in the decision to not leave the judgment of the market about this matter to guesswork. ${ }^{30}$

After reporting that the funds rate operating target would remain at 1.0 percent for another month, and assessing the "balance of risks" ("The Committee judges that, on balance, the risk of inflation becoming undesirably low is likely to be the predominant concern for the foreseeable future"), the statement included a final sentence of a new type: "In these circumstances, the Committee believes that policy accommodation can be maintained for a considerable period." While no outright commitment was made, the minutes indicate that the members in favor of this statement believed it likely "that the Committee would want to keep policy accommodative for a longer period than had been the practice in past periods of accelerating economic activity."

In fact, the committee acted as though they regarded themselves as committed not to raise rates, without some months of advance warning. The "considerable period" language was repeated in the statements released following each of the next three meetings as well (i.e., through the end of 2003). ${ }^{31}$ When the likelihood of

\footnotetext{
${ }^{30}$ Concern about the effectiveness of their communication strategy was also indicated by the fact that the committee scheduled a meeting for September, prior to the next policy decision, to reconsider "its practices regarding the communication of its policy decisions and its assessment of the risks to its objectives.".
} 


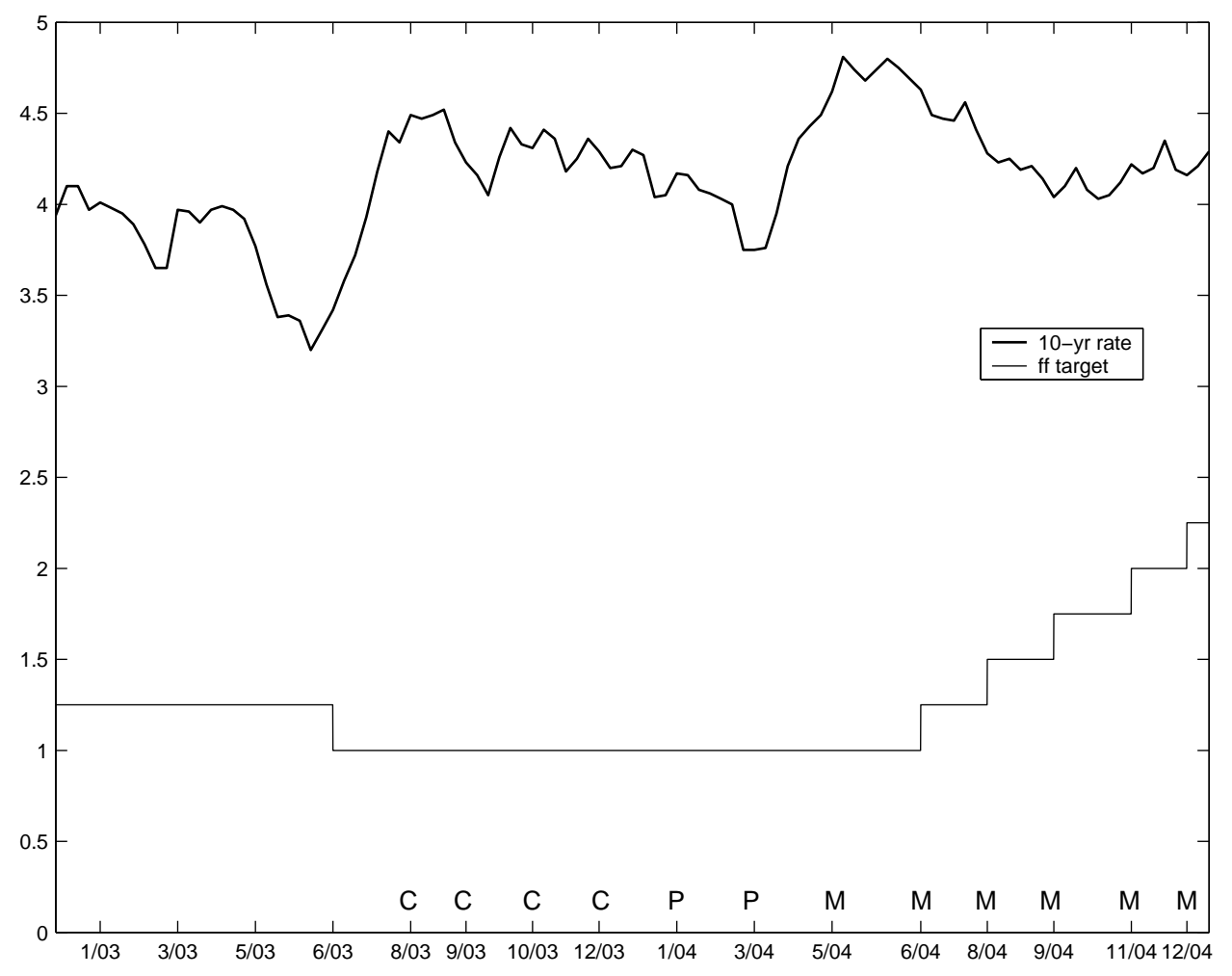

Figure 2: The federal funds rate target and the 10-year Treasury rate. Comments about likely future FOMC policy in post-meeting statements are indicated by letter codes: $\mathrm{C}=$ "considerable period", $\mathrm{P}=$ "patience", $\mathrm{M}=$ "measured pace."

interest-rate increases by the middle of 2004 became apparent, the fact that the funds rate would not remain at 1.0 percent indefinitely was indicated by dropping the "considerable period" language. ${ }^{32}$ Instead, the final sentence of the statement released following the meeting at the end of January 2004 said that "the Committee believes that it can be patient in removing its policy accommodation." According to the minutes, "all the members agreed that a change in wording was desirable, not to signal a policy tightening move in the near term, but rather to increase the

\footnotetext{
${ }^{31}$ The dates on which statements have been released containing various types of language regarding likely future policy are indicated in Figure 2 by the codes ' $\mathrm{C}$ ', ' $\mathrm{P}$ ', and ' $\mathrm{M}$ '. The code ' $\mathrm{C}$ ' indicates a reference to maintaining accommodation for a "considerable period."

${ }^{32}$ The commitment to keep rates low "for a considerable period" had already been qualified in the December 2003 statement, by the inclusion of a reference tying this policy to continued low inflation and resource "slack".
} 
Committees flexibility to take such an action when it was deemed to be desirable and to underline that any such decision would be made on the basis of evolving economic conditions." This language was included again in the March 2004 statement, while the May 2004 statement instead indicated that "the Committee believes that policy accommodation can be removed at a pace that is likely to be measured." Even at this meeting, the funds rate target was not raised; but notice had been given that it would now be raised, albeit at a "measured pace." The funds rate target was indeed raised, beginning at the next meeting; it has now (at the time of writing) been raised by 2.25 percentage points, through a succession of quarter-point increases at nine successive meetings. Throughout this period of steady increases, the post-meeting statements have continued to include the reference to expecting to remove policy accommodation at a "measured pace."

What has the new policy of commenting on the likelihood of future changes in the funds rate target achieved? The "considerable period" language seems to have been intended to influence market expectations in a way that would stimulate additional spending - higher spending, that is, than would have occurred if expectations had been allowed to change in the direction that it was feared they would in the absence of such assurances from the FOMC. As in the scenario described by Eggertsson and Woodford, a statement that interest rates would be kept low for a longer period of time was able to substitute for an immediate cut in rates. ${ }^{33}$ The signal furthermore seemed to be effective. Governor Ben Bernanke, speaking the following year, argued that "the language of the statement in August 2003 and subsequent meetings persuaded the markets that an autumn tightening was not in the cards, and market expectations adjusted accordingly. Crucially, this change in expectations resulted in lower interest rates at all maturities, a development that helped support the expansion in the latter part of last year" (Bernanke, 2004). The decline in the 10-year bond rate following the introduction of this commitment is shown in Figure 2. While bond yields move for a

\footnotetext{
${ }^{33}$ There is no indication in the minutes that the FOMC did not believe that interest rates could ever be cut below one percent. But for whatever reason, no further cut in the funds rate target was made, despite the desire to head off further disinflation, and to signal to the markets that policy would not be tightened as much as was widely believed. In discussing policy in the summer of 2003, Governor Donald Kohn speaks of a funds rate target of zero as having "uncertain consequences," and says that signaling about future policy instead "seemed to be the less-risky way" to stimulate demand (Kohn, 2005). This suggests that there was indeed a reluctance to cut the funds rate target, at least given the existence of an alternative lever of policy.
} 
variety of reasons, this decline even as fears of deflation dissipated and the outlook for the real economy continued to improve suggests that the new communication policy had its intended effect on expectations. ${ }^{34}$

The eventual transition to a higher level for the funds rate has also been managed in a way that has involved few surprises for the markets, and that has not resulted in a bond market rout, sending long rates to levels greater than those consistent with the intended medium-term level of interest rates. As it became clear in the spring of 2004 that the commitment to maintain rates at their existing (historically low) level was about to end, with no indication from the Fed as to how dramatic a change in policy might be coming, long bond yields again rose fairly sharply. But the introduction of the commitment to a "measured pace" in May allowed long rates to decline again, as shown in Figure 2. Since then, it has been possible to increase the funds rate target by a total of two percentage points, while the 10-year bond rate remains (at the time of writing) at about the same level as it was late in 2003, and below the level that it had reached in the summer of 2003, prior to the introduction of the "considerable period" language. This sort of outcome is not especially paradoxical when increases in the funds rate target occur within the context of a funds rate path that was already fairly predictable, so that the increases themselves cause no change in market expectations about the likely level of interest rates over the next several years (and may actually contribute to lower expectations regarding nominal interest rates some years out, insofar as they confirm that the central bank will be vigilant to contain inflation). Bernanke (2004) suggests that the new communications policy has also likely contributed to a recent decline in "overall financial market volatility ... by reducing the uncertainty surrounding the future course of policy."

The degree to which recent decisions about the funds rate operating target have failed to surprise financial markets is shown in Figure 3. In the figure, bars indicate the size of the changes in the FOMC's funds rate operating target that occurred at various dates in the period 2001-04. Associated with each date at which there was a change (or at which there was a meeting at which the FOMC chose not to change the target, so that the announcement of no change was itself news) is an asterisk indicating the size (in basis points) of the component of this change that was

\footnotetext{
${ }^{34}$ Discussing the same period, Governor Kohn (2005) states "I would judge the outcome to have been successful. We did influence rates to better reflect the actual path of policy," with a good outcome for the economy as well.
} 


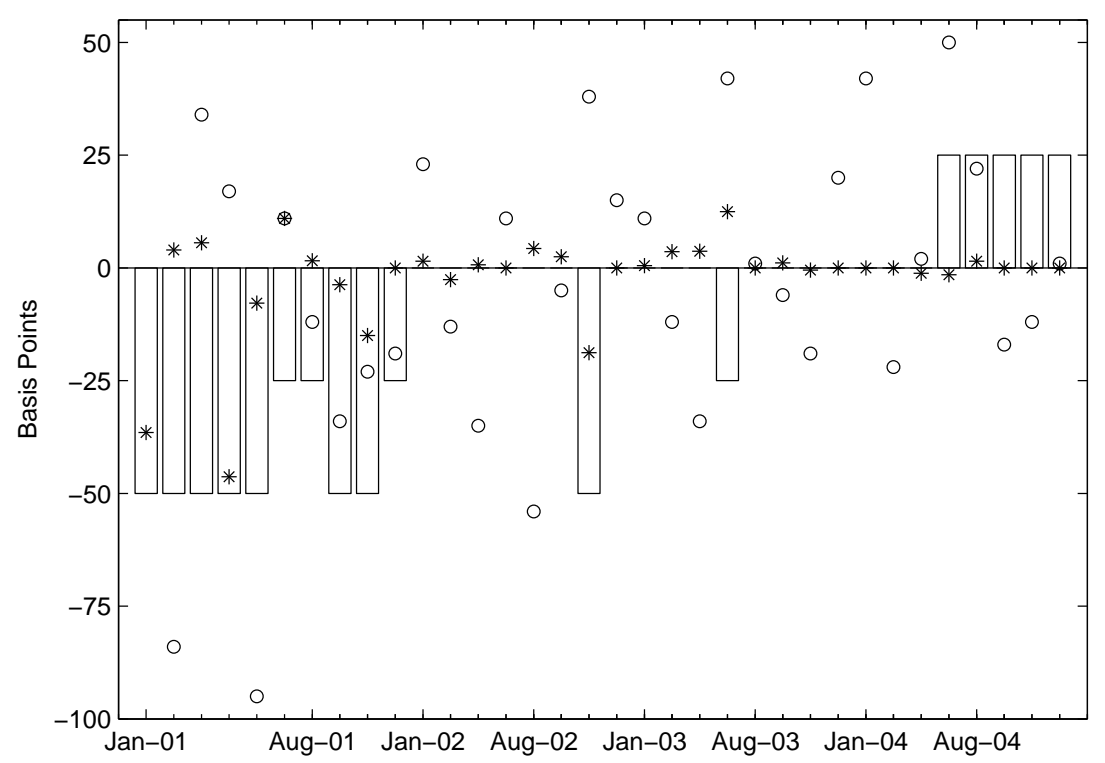

Figure 3: Federal funds rate target changes (indicated by bars), the surprise component of each change (indicated by asterisks), and change in the "slope factor" (indicated by circles). Sources: target changes: Federal Reserve Board; policy shocks: Gurkaynak et al. (2005); slope factor: Gurkaynak (2005).

not already anticipated by financial markets just before the announcement. ${ }^{35}$ One observes that beginning with the August 2003 meeting, the surprise components of federal funds rate target announcements have been extremely small. Surprises were typically larger in earlier periods, even in periods when the target was left unchanged for several meetings in a row, and especially at times when a loosening or tightening cycle began, as in early 2001. Recently, instead, the surprises have been negligible, even when the Fed moved from its constant one percent target to a period of steady tightening.

At the same time, this does not mean that FOMC announcements have failed to affect the markets. In a recent paper, Gurkaynak (2005) investigates the effects of the

\footnotetext{
${ }^{35}$ The surprise components are measured by observing the change in federal funds futures prices for the following month that occurs over a one-hour time window around the announcement. The data on policy surprises are taken from Table 2 of the data appendix to Gurkaynak et al. (2005), available on the IJCB website.
} 
release of FOMC statements on market expectations (as indicated by the fed funds futures market) regarding what the funds rate will be between the current meeting and the next, what it will be after the next meeting, and what it will be after the meeting after that. (The first of these changes in expectations is the "policy surprise" plotted in Figure 3.) Gurkaynak finds that while there has been almost no change in expectations regarding the current funds rate, there have still been changes in expectations regarding what the funds rate will be further in the future.

In particular, what he calls "slope surprises" (indicated by the circles in Figure $3^{36}$ ) - changes in expectations regarding the funds rate two meetings in the future, over and above what one would typically expect given the news about the current funds rate target and the one expected to be chosen at the next meeting - have continued to be about two-thirds as volatile since the fall of 2003 as they were previously, over the period (since early 1998) for which they can be measured. ${ }^{37}$ This indicates that under the new regime, FOMC statements still change expectations regarding the future path of the funds rate - which, as argued above, is essential if they are to effect the economy - but they now achieve this without a need for surprise changes in the current funds rate target. ${ }^{38}$ Insofar as the avoidance of unexpected movements in short-term rates is desirable, to the extent that it is possible without compromising other stabilization objectives, this can be judged an improvement in the skill with which monetary policy is conducted. ${ }^{39}$

\footnotetext{
${ }^{36}$ The values plotted for the slope surprises in Figure 3 are ten times as large as the definition used by Gurkaynak, to make the variations more visible in the figure.

${ }^{37}$ Over the period between January 1998 and June 2003, the root-mean-square size of the slope surprise (under the normalization used in Figure 3) was 0.53, while in the period between January 2001 and June 2003 (shown in the figure), it was closer to 0.54. Between August 2003 and December 2004 (the last FOMC statement in Gurkaynak's sample), the r.m.s. size has been 0.33 - a reduction in volatility, but only a modest one.

${ }^{38}$ In a related analysis, Gurkaynak et al. (2005) decompose changes in the term structure of interest rates upon the release of an FOMC statement into two (orthogonalized) principal components. They interpret the factor that is constructed to be uncorrelated with "policy surprises" as measure of changes in the expected future path of interest rates independent of any change in the current policy rate; as their figure indicates, the volatility of this "path factor" has also remained as large since August 2003 as it had been before.

${ }^{39}$ The observation that funds rate decisions are no longer surprises on the day of the meeting under the new regime contrasts with the findings of Ehrmann and Fratzscher (2005) about the effects of the Fed's change in disclosure policy in 1999. They find that funds rate decisions were not any more predictable on the day of the meeting under the regime where the FOMC released a
} 
The primary difficulty associated with the new policy of signaling funds rate target changes in advance has been some degree of discomfort, among at least some members of the FOMC, with the degree to which statements of this kind constrain the policy decisions that can be made at later meetings. ${ }^{40}$ Of course, one of the advantages of such statements that I have suggested above is precisely that they can constrain a policy committee to not behave in the way that would otherwise seem appropriate ex post; such constraint can be desirable, because of the benefits that flow from being anticipated to conduct policy in a history-dependent fashion. For example, in the case of the optimal state-contingent policy depicted in Figure 1, it would be important that the central bank feel itself constrained not to raise interest rates in quarter 15, despite the fact that it has learned that (relatively unexpectedly) the natural rate of interest has returned to its normal, positive level, and despite the fact that failing to do so means creating a mildly inflationary boom. Policymakers who reason like discretionary optimizers will indeed be uncomfortable with such behavior, and they would be right to anticipate - when considering the advisability of such a commitment at the earlier time - that they will subsequently find the commitment an annoying constraint. But a policymaker who thinks more deeply should realize that it is nonetheless desirable to constrain oneself, at least in the case that the constraint can be expected to be understood by the public.

But in all likelihood, the discomfort is not solely due to a failure to understand the logic of Kydland and Prescott (1977), but also to frustration with the crudeness of the kinds of commitments that can be made using such simple statements as the ones just paraphrased. The signals that have been given thus far through the post-

\footnotetext{
"balance of risks" statement than they had been previously, though they do find that the increased communication after 1999 did have the effect of increasing the degree to which funds rate decisions could already be forecasted by the markets immediately following the previous FOMC meeting (so that less learning occurred during intermeeting periods under the new regime), and also that FOMC meetings contributed less to financial market volatility under the new regime. Thus while the post1999 "balance of risk" statements did increase the forecastability of policy (albeit not at such short horizons as a day in advance), the new policy signaling regime appears to be even more effective at this.

${ }^{40}$ For example, the minutes for the May 2004 meeting, at which the "measured pace" language was introduced, reports that "a number of policymakers were concerned that such an assertion could unduly constrain future adjustments to the stance of policy should the evidence emerging in coming months suggest that an appreciable firming would be appropriate," though all members eventually endorsed the language adopted.
} 
meeting statements all attempt to say something about the likely path of the funds rate for the next several months; they refer (in a way that is open to interpretation) to rates of change and periods of time, but, except for the constant qualification that the statement is only an indication of "likely" policy, they do not speak of the way in which future policy should be contingent on circumstances that are not already evident. If the statements are interpreted as commitments to particular non-statecontingent paths for the funds rate - albeit commitments that specify the path only for a fairly short distance ahead — then they are likely to constrain policy in ways that are not fully ideal.

For while an optimal policy commitment will generally imply that policy should be history-dependent, as stressed above, it will also generally imply that policy should be state-contingent as well. For example, in the policy problem considered by Eggertsson and Woodford (2003), the optimal policy involves keeping the nominal interest rate at its lower bound for several quarters even after the natural rate returns to its normal level; but the exact number of quarters for which this should be done depends on the evolution of the exogenous disturbance, and is not known until date $T$ is reached. Moreover, the fact that, in the particular numerical exercise considered in Figure 1, it is possible to make a definite commitment once period $T$ is reached depends on the fact that there is assumed to be no further uncertainty about the evolution of fundamentals after date $T$. In the case of a more general disturbance process $\left\{r_{t}^{n}\right\}$, the number of periods for which interest rates should be kept low will also depend on the path of the natural rate after it has again become positive; under an optimal policy, the central bank would not generally know whether it was yet time to raise rates until the time to do so was reached.

The kind of commitment that needs to be communicated, in order to allow a closer approximation to fully optimal policy, is one that would indicate the way in which future policy should depend on future economic developments. This might seem so complex as to not be usefully explained to the public; but my own view is that even a very general indication of the kind of factors that should be crucial for future policy decisions would greatly help to clarify the public's view of the likely state-contingent evolution of interest rates and of the economy. In the context of the simple policy problem considered above, Eggertsson and Woodford show that the optimal time and degree to which interest rates should eventually be raised can be explained in terms 
of a fairly simple formula. Under the policy rule that they propose, ${ }^{41}$ the central bank should set its policy rate so as to achieve a particular pre-announced target level for an output-gap-adjusted price-level target, ${ }^{42}$ to the extent that this is consistent with the interest-rate lower bound. The interest rate will thus be kept at the lower bound as long as it continues to be impossible to reach (or exceed) this target, even with interest rates at the lower bound; rates should be raised above the lower bound once the target level for the output-gap-adjusted price level is reached, and not sooner. A commitment of this kind would imply that the lower-bound policy should be expected to continue for a considerable period, in the case that the output-gap adjusted price level is currently well below the target; and a policy commitment that emphasized this target (and hence the size of the gap that would remain to be closed at any given time) would even allow the private sector some basis for judging the likely length of such a period. But it would also automatically imply that increases in interest rates would likely be appropriate soon, as the gap with respect to the target shrank, and would furthermore provide guidance as to how policy should be expected to be conducted thereafter, all without any need for a change in the language of the commitment. And it would be a form of commitment that would make evident the state-contingency of the implied path of interest rates.

The FOMC has made some effort to communicate the contingent nature of its statements about the outlook for future policy. ${ }^{43}$ In December 2003, the statement that rates were likely to remain low for a "considerable period" was explicitly linked to the observation of "inflation quite low and resource use slack." According to the minutes of the January 2004 meeting, this language had been intended to "underscor $[\mathrm{e}]$ the notion that a move away from the current degree of policy accommodation would depend on economic conditions rather than simply on the passage of time."

\footnotetext{
${ }^{41}$ Other approaches to the implementation of the optimal state-contingent policy in a similar model are discussed by Svensson (2004) and by Sugo and Teranishi (2005).

${ }^{42}$ This variable is equal to the log price level plus a positive multiple of the output gap. Thus the price level target is automatically increased slightly in the event of a negative output gap.

${ }^{43}$ Bernanke et al. (2004) note that during the period of the FOMC's commitment to keep rates low for a "considerable period," each FOMC statement also discussed labor market conditions, which might have been interpreted as indicating that a change in the policy would be conditional upon labor market developments. As evidence in support of the conditionality have been understood by market participants, they find that Treasury yields became more responsive to news in the monthly payroll number in the employment report during this period.
} 
These minutes also indicated that the language adopted in the statement released after the January meeting, referring to "patience" rather than to a "considerable period," was intended to indicate more clearly that an increase in interest rates later in the year was possible, "and to underline that any such decision would be made on the basis of evolving economic conditions." While the reference to "patience" itself may have been a rather cryptic way of indicating that policy would be state-contingent, the eventual publication of the minutes would have made this clearer; and the current policy of expedited release of the minutes makes the possibility of clarifying the state-contingent character of future policy through the minutes, rather than through the post-meeting statement itself, a realistic possibility. ${ }^{44}$

It would likely be desirable for the FOMC to experiment further with clarifications of this kind. As the period in which regular quarter-point interest-rate increases at each meeting were fully predictable comes to an end, it will become more important for the FOMC to attempt to communicate about the state-contingent character of policy, if it is to comment on future policy at all. Recent experience suggests that comments on future policy can help, both in reducing the number of policy surprises and in keeping bond-market expectations in line with the FOMC's own outlook for rates over the medium term, and these indications of success in steering expectations should increase the effectiveness of policy. But a continuation of this success under more normal circumstances will require the development of more flexible ways of speaking about the likely character of future policy.

\section{Assumptions About Future Policy in Inflation- Forecast Targeting}

Probably the most important advances in communications policy over the past ten to fifteen years have been made by the inflation-targeting central banks, among which banks such as the Sveriges Riksbank, the Bank of England, and the Reserve Bank of New Zealand have been especially important innovators in the development of new methods of communication with the markets and the general public. The Inflation

\footnotetext{
${ }^{44}$ Governor Kohn (2005) lists as an important reason for the earlier release of the minutes the desire to "help spell out the linkage the Committee may see between any policy inclination and its economic outlook" and "convey the conditionality of Committee thinking."
} 
Reports of these banks provide good practical examples of communication with the public about the central bank's policy commitments. These reports do not pretend to give a blow-by-blow account of the deliberations by which the central bank reached the position that it has determined to announce; but they do explain the analysis behind the decision that has been reached. This analysis provides information about the bank's systematic approach to policy by illustrating its application to the concrete circumstances that have arisen since the last report; and it provides information about how conditions are likely to develop in the future through explicit discussion of the bank's own projections. Because the analysis is made public, it can be expected to shape future deliberations; the bank knows that it should be expected to explain why views expressed in the past are not later being followed. Thus a commitment to transparency of this sort helps to make policy more fully rule-based, as well as increasing the public's understanding of the rule.

The periodic publication of Inflation Reports is a key element in the kind of policy regime that Svensson (1999) calls "inflation-forecast targeting." Under this approach, the central bank does not only announce a quantitative target (its inflation target) that defines the goal of policy. It is also committed to a particular kind of decision procedure, under which projections are made of the future evolution of inflation and other variables under a particular assumed stance of policy, and the assumed policy is to be implemented (until the matter is reconsidered in the next decision cycle) only if the projections satisfy a certain target criterion. For example, in the case of the Bank of England, the criterion given primary emphasis (at least in the public justification of the policy decisions that are taken) is one that requires projected CPI inflation to equal 2.0 percent at a horizon eight quarters in the future. ${ }^{45}$ And finally, it explains its policy decisions to the public in terms of their conformity with the target criterion. In the case of the central banks just mentioned, this means the publication of Inflation Reports several times per year, that give prominent attention to the projections that justify the current stance of policy.

While the development of inflation-forecast targeting represents a substantial advance, both in the commitment of central banks to the conduct of policy in accordance with an explicit rule and in the transparency of communication with the public about

\footnotetext{
${ }^{45}$ Before 2004, the criterion required the projection of a different inflation measure, RPIX inflation, to equal 2.5 percent at the 8-quarter horizon (Vickers, 1998; Goodhart, 2001). The change in target criterion is discussed in Bank of England (2004a).
} 
policy deliberations, the precise techniques that are used continue to be refined. One of the most debated aspects of current practice has been the question of what kind of assumption to make about the future conduct of policy when preparing the projections that will be used to judge the appropriateness of current policy.

\subsection{Constant-Interest-Rate Projections}

Computation of projected paths for variables such as inflation and output some years into the future requires that one make assumptions about the future conduct of monetary policy - at least over the horizon of the projection, and, in the case of a model of the transmission mechanism that incorporates forward-looking behavior by the private sector, even farther. This is a particularly delicate aspect of such exercises, because of the implied need for the central bank to take a stand on the question of how it is likely to conduct policy in the future, and even more critically, because of concern that public discussion of the assumptions being made could be interpreted as a statement of the bank's intentions. Statements of intentions regarding future policy have often been regarded as problematic, for reasons of the kind already discussed above.

A common way of seeking to avoid any statement about future policy has been to base policy deliberations - or at least, the way these deliberations are presented in the banks' Inflation Reports - on projections of the future evolution of inflation and other variables under an assumption that the interest-rate target (repo rate) will remain constant over the horizon of the projection, at the level that is chosen currently. (This was, for example, the assumption made in the base-case projections that were presented in the overview section of the Bank of England Inflation Reports, prior to August 2004; and it is still the assumption made in the base-case projections in the Inflation Reports of the Sveriges Riksbank.) The policy decision is then a search for an interest rate with the property that constant-interest-rate projections assuming that particular rate satisfy a particular target criterion (for example, projected CPI inflation of 2.0 percent two years in the future). ${ }^{46}$ The Inflation Reports then justify the interest-rate decision that has most recently been made by presenting these

\footnotetext{
${ }^{46}$ Former Bank of England MPC member Charles Goodhart (2001) describes himself as having tried to set interest rates in this way, and says "This was, I thought, what the exercise was supposed to be" (p. 177). Jansson and Vredin (2003) describe the similar procedure used by the Sveriges Riksbank.
} 
projections and noting that they conform fairly well to the criterion in question.

This way of avoiding any need for the central bank to show its cards with regard to future policy has the advantage of being simple to explain to the public - as long as the public is not sophisticated enough to ask what it really means - but has a number of unappealing implications. ${ }^{47}$ First of all, many optimizing models of the monetary transmission mechanism have the property first demonstrated by Sargent and Wallace (1975) for a rational-expectations IS-LM framework, namely, that the equilibrium path of the price level (and hence of the inflation rate) is indeterminate under the assumption of a fixed nominal interest rate (or indeed, any exogenously specified interest-rate process). ${ }^{48}$ If such a model were to be used for the central bank's projection exercise, the staff would be unable to compute predicted paths for inflation or other variables under the hypothesis of any constant level of nominal interest rate, and so unable to assert that one particular level would imply satisfaction of the target criterion. ${ }^{49}$

Alternatively, many backward-looking models (including optimizing models in which expectations are assumed to be based on extrapolation from past time series) have the property discussed by Friedman (1968), namely, that maintaining a constant nominal interest rate indefinitely will lead to explosive inflation dynamics, through a Wicksellian "cumulative process." 50 Goodhart (2001) suggests that the Bank of England's model has this latter property, and that as a result, "the rate of change of most variables visible at the two-year horizon in the Bank's forecast generally (though not invariably) tends to persist, and on occasion to accelerate, in the third and subsequent years" (p. 171). ${ }^{51}$ An example of this property is shown in the

\footnotetext{
${ }^{47}$ Goodhart (2001) reviews what he calls "the prima facie case against" this approach before offering his defense of it. Other critical discussions include Leitemo (2003), Svensson (2003), and Honkapohja and Mitra (2003).

${ }^{48}$ See Woodford (2003, chap. 4) for further discussion.

${ }^{49}$ Leitemo (2003) discusses possible interpretations of the constant-interest-rate projection exercise that would allow it to yield a policy recommendation even in the case of a forward-looking model of the transmission mechanism; but these do not eliminate the other unappealing features of such a procedure.

${ }^{50}$ See Bullard and Mitra (2002) and Preston (2005) for analyses of forward-looking models with least-squares learning by the private sector.

${ }^{51}$ Goodhart (2005) indicates that "in medium run simulations at the Bank of England running much beyond [a] two-year horizon, the constant two-year rate assumption had to be linked into a Taylor-type reaction function to prevent nonsensical trends from developing as the horizon extended
} 
box on pp. 42-43 of the August 2004 Inflation Report (Bank of England, 2004b), where the constant-interest-rate inflation projection from the February 2004 report is extended another year into the future. While the projection showed CPI inflation rising to about 2.0 percent, under the most likely scenario, by early 2006, it showed inflation continuing to rise, to about 2.4 percent, by early 2007, with no indication of convergence even at that level. In this case, it is possible to ask which constant interest rate would imply satisfaction of the target criterion at a certain finite horizon, but only at the expense of making it clear that hitting the target at (say) the 8-quarter horizon does not also imply expecting to hit it in subsequent quarters. Hence it cannot be the case that one expects to be content to maintain the constant-interestrate policy indefinitely, even in the absence of any developments that cannot already be foreseen.

Moreover, if one's model currently implies that inflation will depart significantly from the target rate at the three-year horizon if interest rates are maintained at their current level for that long, then it also implies that one should expect that a year from now - barring unforeseen developments - if interest rates have been maintained at their current level, it will then be forecasted that inflation will depart from the target at the two-year horizon if interest rates are not changed. For example, in the case just mentioned, the projection in February 2004, based on an assumption that the repo rate would remain at 4.0 percent over the following three years, implied showed CPI inflation accelerating to about 2.4 percent by early 2007. But this projection would then imply that under the most likely scenario, keeping the repo rate at 4.0 percent throughout 2004 would be expected to result in the Bank's projecting in February 2005 that CPI inflation should reach 2.4 percent in only two years, at which point (if not sooner), the exercise should require the repo rate to be raised. Thus the projection would imply that one should not expect the repo rate to remain at its current level for an entire year, even in the absence of any "news". It should have been expected to be raised fairly soon, as indeed it was (by 75 basis points over the next six months).

beyond two years (p. 7)." Goodhart argues that this does not present any problem for an exercise in which the constant-rate assumption is maintained only over a two-year horizon. But if one admits the acceptability of imposing a reaction function as the policy assumption beyond the two-year horizon, it is unclear why one should not be willing to impose a reaction function for earlier dates as well, at least to the extent that the MPC is not willing to take a stand on a particular direction of likely near-term deviation from the 'typical' reaction function. 
The publication of constant-interest-rate projections - and the public justification of policy decisions by reference to them - is in no way intended to suggest that the central bank intends to maintain interest rates constant over the period of the projection. (Indeed, the most important justification for the use of constant-interestrate projections seems to be a desire not to express any intention regarding future policy.) Nor can it be defended as representing the central bank's own best current estimate of the future path of interest rates; after all, the implication of the projections explained above would be evident above all within the central bank itself. ${ }^{52}$

But this implies that the targeting procedure is based on forecasts that are not actually believed, even in the central bank itself. Such a procedure has the paradoxical implication that the central bank may choose a policy under which it does not truly expect the target criterion to be satisfied, though it may believe that it would be under the counterfactual hypothesis of the constant interest rate. ${ }^{53}$ Such a state of affairs can hardly be defended as conducive to transparency in the conduct of monetary policy. If policy is genuinely based on constant-interest-rate conditional projections, then one's policy decisions are not aimed at ensuring satisfaction of the

\footnotetext{
${ }^{52}$ Even before the Bank of England ceased to use the constant-interest-rate projections as the base case in its Inflation Report, it was fairly clear that these projections did not represent the Bank's own forecast of how the economy was most likely to evolve. This was conceded at least implicitly in the Bank's published discussions of the accuracy of its projections, for example in the Inflation Reports of August 2001 and August 2002. In these discussions, the Bank gave exclusive attention to the projections that it also published in which an interest-rate path was assumed corresponding to current market expectations, rather than to the projections conditional on the constant interest-rate path. If the Bank regarded the constant-interest-rate assumption as the best available forecast of its behavior, it would want to test the accuracy of the projections made under that assumption, rather than under contrary assumptions that might be made by traders in financial markets.

${ }^{53}$ In the case of the February 2004 projections of the Bank of England already discussed above, the constant-interest-rate projection used as the main basis for policy deliberations at the time indicated inflation near 2.0 percent at the 8-quarter horizon, but surging above two percent over the next year. As shown in the Bank's subsequent discussion of its decision to de-emphasize the constant-interestrate projections (Bank of England, 2004b, pp. 42-43), a projection based on market anticipations regarding the future path of interest rates (according to which interest rates would soon be raised above the 4.0 percent decided upon in February) instead implied that inflation should remain well below two percent over the entire two-year period, though this projection would imply an inflation rate nearing two percent if extended three years into the future. If the latter projection were really the one regarded as more realistic by the MPC in February, this would imply that they were not really basing their decision on projected inflation at the 8-quarter horizon.
} 
target criterion that is announced to the public; and the projections published by the central bank are not accurate forecasts that should better help the private sector to correctly anticipate the economy's evolution. On the other hand, if the central bank genuinely does expect the target criterion to be satisfied, then policy is not actually determined in the way that the official rhetoric implies that it is; and if the forecasts are unbiased, then they are not the kind of forecasts that they are officially described as being.

\subsection{Projections Based on Market Expectations}

The Bank of England has evidently accepted the force of at least some of the criticisms that have been raised of the use of constant-interest-rate projections, and since the August 2004 Inflation Report it has ceased to emphasize those projections in its justification of current policy. ${ }^{54}$ It now focuses its evaluation of policy on a set of projections that are conditional on the path of short-term interest rates implied by the term structure of yields on longer-term Treasury securities. ${ }^{55}$ This allows the projections to be based on a more realistic assumption regarding future interest rates, while still allowing the MPC to remain silent as to whether the interest-rate assumptions used in the projection exercise agree with their own. ${ }^{56}$ The way in which

\footnotetext{
${ }^{54}$ The Minutes of the monthly Monetary Policy Committee meetings in 2004 indicate considerable emphasis on the projections based on market expectations, as opposed to the constant-interest-rate projections, in the actual policy decisions from at least March 2004 onward. The August Inflation Report was the first one to recognize this change in the MPC's thinking by presenting the marketexpectations projections as the base case.

${ }^{55}$ The Sveriges Riksbank has also begun, in its 2005:Q1 Inflation Report, to give more prominence to projections conditional on an interest-rate path inferred from the term structure. However, the Riksbank continues to base its "main scenario" on the assumption that the repo rate will remain unchanged. The alternative scenario is also presented, late in the report, to "provide a broader base for discussions of monetary policy" (Sveriges Riksbank, 2005, p. 5), but is not referred to in the main discussion of inflation risks under current policy. The Inflation Reports of Norges Bank currently give greatest prominence to a baseline scenario in which the interest-rate assumption is described as "based on market interest rate expectations" (see, e.g., Norges Bank, 2005, p.2), but which seems actually to represent a view of the Bank itself as to the most likely path of interest rates, as discussed further below.

${ }^{56}$ The explanation of the interest-rate assumption includes the following qualification: "It is important to stress that the market rate path does not represent the MPC's forecast of official interest rates.... Financial markets may judge economic prospects differently from the MPC" (Bank of
} 
these projections are used in the MPC's decision procedure has not been explicitly discussed. Apparently, the idea is that if the projections based on market expectations satisfy the target criterion, then the MPC should set the repo rate at the level expected by the markets. Thus in August 2004 the rate was raised from 4.50 to 4.75 percent, to conform to market expectations of a repo rate averaging 4.6 in 2004:Q3 and rising to an average of 4.9 in 2004:Q4. In November 2004, it was left unchanged, because market expectations at this time forecasted only an average of 4.7 in both 2004:Q4 and 2005:Q1; and in February 2005, it was again left unchanged, because this continued to be what the markets expected. ${ }^{57}$ If the projections based on market expectations were to fail to satisfy the target criterion, then presumably policy should deviate from the market expectation, though it is not clear by how much; this situation appears not yet to have arisen.

While this alternative avoids some of the problems associated with constantinterest-rate projections, it does not avoid all of them, and introduces some new problems of its own. ${ }^{58}$ The problems of inconsistency that arise when policy deliberations (or at least the public justification of these deliberations) are based on an interest-rate assumption different from what the MPC believes is most likely to occur remain, as long as the assumed path does not actually represent the MPC's forecast. The new approach makes the contradiction less glaring, since it is no longer obvious in which particular way the MPC should be expecting something different from what is assumed. But if the MPC does disagree with the assumed interest-rate path, the procedure is still incoherent and/or misleading; and it is hard to see how continued coyness of the MPC as to whether it agrees or not with its stated assumptions can serve the goal of clarifying the way in which policy is conducted.

The problem that the interest-rate assumption would not allow an equilibrium path to be computed, in the case of a standard forward-looking model, or would imply unstable dynamics, in the case of many backward-looking models, is also not avoided by the new proposal. These problems arise whenever a path for the nominal interest rate is assumed, that is independent of the evolution of the endogenous variables in the model; they have nothing to do with the constancy of the assumed

\footnotetext{
England, 2004b, p. 41).

${ }^{57}$ See Table 6.A, "Market expectations of the Bank's official interest rate," in each of these issues of the Inflation Report.

${ }^{58}$ See also Goodhart (2005) for criticism of the new procedure.
} 
path. ${ }^{59}$ When a particular path for interest rates is inferred from the term structure and plugged into a model of the monetary transmission mechanism as if it were given exogenously, the same problems will arise as in the case of a constant-interest-rate assumption. (Even if nominal interest rates are assumed to rise over the coming year, the fact that they are assumed to rise by an amount independent of any increase in inflation gives rise to unstable dynamics: higher inflation will lower the real interest rate, stimulating higher inflation, and so on.) The only solution for this problem is to include in one's model a realistic representation of endogenous variation in short-term nominal interest rates.

At the same time, a decision procedure using projections based on market expectations introduces some new problems. Most importantly, it runs the risk of making policy too sensitive to market expectations regarding policy, in a way that fails to provide any anchor for those expectations or any stable course for policy. Consider an extreme version of the approach to policy sketched above, in which the central bank simply infers market expectations regarding the path of its policy rate, and sets the rate in accordance with market expectations. As Blinder (1998) points out, "following the markets" in this way would be quite dangerous, for there would then be no reason for the markets to expect one kind of policy rather than any other; arbitrary notions could easily become self-fulfilling, and the sources of significant instability and/or inefficiency.

Of course, the approach to policy that has apparently been adopted by the Bank of England is more sophisticated than that; there is no commitment to follow the markets' lead, unless the Bank's projections imply that doing so is consistent with a projection of inflation near two percent two years in the future. But it is not clear

\footnotetext{
${ }^{59}$ Here I am interpreting a projection based on "market expectations" as one that computes a particular forward path for interest rates from the term structure, and then substitutes that interest-rate path into the structural model as the specification of monetary policy. One could imagine carrying out such an exercise in other ways - in the next section I discuss an alternative - and it is not clear from published discussions exactly what kind of computations are undertaken by the Bank of England staff. But the interpretation discussed here is not only the simplest version of such an exercise, it is the only version that would allow a central bank to avoid making any assumptions of its own about how it will conduct policy in the future. Thus even if it is not the kind of projection exercise currently used at the Bank of England, it is a type of exercise that might well be attempted by a central bank seeking to follow their lead in using projections based on market expectations.
} 
to what extent such a qualification should succeed in preventing fluctuations due to self-fulfilling expectations. This is because, even when arbitrary fluctuations of that kind occur, inflation may still be (correctly) predicted at any point in time to revert back to its target level within a few quarters.

As an example, consider the simple model of the monetary transmission mechanism discussed above, according to which inflation and output are determined each period by equations (2.1) and (2.2). Let $s_{t}$ be an exogenous random process that has no relation to economic "fundamentals" 60 — what is sometimes called a "sunspot" variable - and suppose that its dynamics can be described by a first-order autoregressive equation,

$$
s_{t}=\rho s_{t-1}+\epsilon_{t},
$$

where $0<\rho<1$ is the coefficient of autocorrelation and $\left\{\epsilon_{t}\right\}$ is a bounded white-noise disturbance. I wish to consider the possibility of an equilibrium in which inflation and output fluctuate in response to variation in the sunspot variable, simply because people have come (for arbitrary reasons) to expect this, and have observed that the variable does indeed help them to forecast the economy's future evolution. Consider, for example, the possibility of an equilibrium in which

$$
\pi_{t}=\phi s_{t}
$$

for some coefficient $\phi \neq 0$. Equation (2.1) will be satisfied as long as the equilibrium fluctuations in the output gap are given by

$$
x_{t}=\frac{1-\beta \rho}{\kappa} \phi s_{t}
$$

Equation (2.2) will also be satisfied as long as the nominal interest rate satisfies

$$
i_{t}=r_{t}^{n}+\left[\rho-(1-\rho)\left(\frac{1-\beta \rho}{\kappa}\right) \sigma^{-1}\right] \phi s_{t}
$$

Now suppose that in each period $t$, the exogenous state of the world (including the current values of $r_{t}^{n}$ and $s_{t}$ ) is first revealed; then futures markets are open, in which traders bet on the value of that period's interest rate $i_{t}$; and finally, the central bank chooses its operating target for $i_{t}$, after learning the market forecast $i_{t \mid t}$

\footnotetext{
${ }^{60}$ In particular, it is unrelated to the real factors that cause variation in either the natural rate of output or the natural rate of interest.
} 
implied by the futures prices, and period $t$ inflation and output are then determined in accordance with equations (2.1) - (2.2). In the equilibrium just conjectured, the market expectation should be given by

$$
i_{t \mid t}=r_{t}^{n}+\left[\rho-(1-\rho)\left(\frac{1-\beta \rho}{\kappa}\right) \sigma^{-1}\right] \phi s_{t} .
$$

If the central bank observes this, and sets $i_{t}=i_{t \mid t}$, then (3.2) will be satisfied, and the equations given above for inflation and output will represent a rational-expectations equilibrium.

But should the central bank be willing to follow the markets and set $i_{t}=i_{t \mid t}$ ? In the equilibrium just described, a correct forecast of the future path of inflation will in any period be given by

$$
E_{t} \pi_{t+j}=\rho^{j} \phi s_{t}
$$

for arbitrary $j \geq 0 .{ }^{61}$ If the central bank forecasts in this way, conditional on policy that coincides with market expectations, it will conclude that the inflation rate should converge back to its long-run target value (here assumed to equal zero ${ }^{62}$ ) as the horizon $j$ is extended farther into the future; and this will be true no matter how large $\phi$ is, and hence no matter how large the short-run fluctuations in inflation and output due to self-fulfilling expectations may be. Furthermore, if $\rho$ is not close to 1 , the convergence will be predicted to be nearly complete after only a few quarters. ${ }^{63}$

\footnotetext{
${ }^{61}$ Substitution of the interest rate path $\left\{i_{t+j \mid t}\right\}$ expected by the markets into the model consisting of equations (2.1) - (2.2) would not yield this as the only possible equilibrium, because of the indeterminacy problem already referred to in the case of any exogenously specified interest-rate path. But it would be one possible projection consistent with both the model and with market expectations regarding the path of interest rates; and since it is the correct forecast, in the conjectured equilibrium, I shall suppose that the central bank is sophisticated enough to produce this forecast.

${ }^{62}$ For simplicity, I here assume that the target inflation rate is zero. This allows me to avoid discussing the question whether it makes sense to suppose, as in the Calvo pricing model used here, that prices should remain fixed in nominal terms between the occasions on which they are reoptimized, even when the central bank's target rate of inflation is positive and inflation is positive on average. The point made here about the possibility of sunspot equilibria in which inflation reverts quickly to the target level would be equally valid if the target rate of inflation were assumed to be positive.

${ }^{63}$ For example, in the case that $\rho=0.7$ and periods represent quarters, one could have an equilibrium in which actual inflation varies over a range as wide as 6 percentage points ( 3 points above and below the target), solely as a result of self-fulfilling expectations, but in which projected inflation 8 quarters in the future would never be more than 10 basis points away from the target.
} 
It is thus not obvious that a central bank that pays attention only to the projected inflation rate two or more years in the future would find any reason not to follow the markets at all times, even if this policy allowed large transitory fluctuations in inflation (and associated large swings in output relative to potential) to occur, due solely to self-fulfilling expectations. ${ }^{64}$

One might argue that in the case just described, the possibility of fluctuations in response to the sunspot disturbance would be eliminated as long as the central bank were to establish a reputation for responding to even small departures of the projected inflation rate two years in the future from the target value. For example, if the central bank were to commit itself to a rule of the form

$$
i_{t}=i_{t \mid t}+\psi \hat{E}_{t} \pi_{t+8}
$$

for some coefficient $\psi>0$, where $\hat{E}_{t} \pi_{t+8}$ represents the central bank's projection of inflation 8 periods in the future, conditional on its conducting policy in the way anticipated in the futures markets, then the only possible rational-expectations equilibrium would have to be one in which $E_{t} \pi_{t+8}=0$ at all times. This would preclude any equilibrium of the kind conjectured above, except the one with $\phi=0$. However, this result depends on assuming that the central bank would respond systematically (albeit to only a small extent) to even small departures from satisfaction of its target criterion, which seems unlikely given that the policy rate is ordinarily moved only in discrete steps. More to the point, even rule (3.3) would allow the existence of sunspot fluctuations of arbitrary amplitude, in the case of a sunspot variable $s_{t}$ that evolved as an MA(7) process (or any lower-order MA process), so that $E_{t} s_{t+8}=0$ at all times.

Another problem with the current procedure of the Bank of England is that it is unclear how the MPC is intended to determine the correct current repo rate in the event that the interest-rate path expected by the markets is judged to imply projections inconsistent with the Bank's target criterion. Would an attempt be made to determine the current repo rate that would lead to an acceptable projection, under the assumption that the path of the repo rate after the current month would follow the path anticipated by the markets? This would typically require an extreme adjustment

\footnotetext{
${ }^{64}$ The problem just described arises because of the use of a target criterion that involves only the economy's projected state 8 quarters and more in the future; it could be eliminated by the use of a nearer-term target criterion. This would be desirable on other grounds as well, as discussed in Woodford (2004).
} 
of the current repo rate, as a change in the repo rate for only one month would have to change the path of inflation over the following two years by enough to get the projected inflation rate two years in the future on track. A more sensible approach would surely involve adjusting the entire path of interest rates to one that the MPC would view as more sound, rather than acting as if the committee expected itself to behave in the future in the way currently anticipated by the markets, even though it was planning to depart substantially from the markets' expectation in the short run. But in this case, projections would have to be produced on the basis of an assumption about future policy other than the one corresponding to market expectations. The idea that the MPC would be able to avoid taking a stand (at least in its internal deliberations) on a reasonable future path of interest rates, by insisting on using the markets' forecast in its projections, is not tenable.

\subsection{Projections Based on a Model of Central-Bank Behavior}

The kind of forecast-targeting procedure recommended by Svensson and Woodford (2005) as a way of implementing optimal monetary policy is of a different sort than either of the two approaches just discussed. In this procedure, one projects the economy's future evolution under alternative contemplated policy decisions, assuming that in future decision cycles the central bank will again act to ensure satisfaction of the target criterion. This amounts to asking what action is needed in order to project that that the criterion should be satisfied in the current period, taking as given that it is expected to be satisfied in later periods (as a result of the policy actions to be taken in those periods). Such a calculation yields a determinate outcome as long as there is a determinate rational-expectations equilibrium implied by the target criterion; this is always the case if the target criterion is selected according to the method of Giannoni and Woodford (2002).

Thus I would argue that policy should be based on a projection exercise that includes a model of the central bank's own future behavior - one that is furthermore consistent with the procedure that it actually follows in making its policy decisions. This is the kind of projection exercise used as the basis for policy decisions at some central banks, notably the Reserve Bank of New Zealand, which also publishes some information about the non-constant interest-rate path implicit in its projections, along with its projections for inflation and other variables. ${ }^{65}$ 
Charles Goodhart $(2001,2005)$ objects that such a procedure is impractical, on the ground that it would be much more difficult for a monetary policy committee to reach agreement on an entire future path for interest rates, rather than allowing them to decide only about the current interest rate each time they meet. But the procedure described by Svensson and Woodford does not involve a multi-dimensional decision problem in each decision cycle. As with the constant-interest-rate projection method, one makes a decision for the current period only, on the basis of projections of the future that (necessarily) incorporate a hypothesis about future policy; the hypothesis about future policy is simply a more realistic one than the notion that interest rates will not change, regardless of how inflation and output evolve. And there is no greater need for agreement among the members of the policy committee about that particular aspect of the model specification than about the other assumptions involved in making projections for the future. ${ }^{66}$ The fact that the Inflation Reports of Norges Bank have begun to include projected paths for money-market interest rates that (at least for the final two years of the projection period) represent the judgment of the Bank rather than market expectations also suggests that agreement on a path is not necessarily such a complex multidimensional decision.

Goodhart also argues that revealing a projected non-constant path for interest rates is problematic, because "any indication that the MPC is formally indicating a future specific change in rates ... would be taken to indicate some degree of com-

\footnotetext{
${ }^{65}$ The models used at some other banks, such as the Bank of Canada, similarly include equations intended to represent future policy; but these banks do not publish their projections. Norges Bank is another inflation-forecast-targeting central bank that has recently begun to publish projections based on a non-constant interest-rate path that appears to represent the Bank's own view of the most likely scenario, though it is unclear how this path is determined. The interest-rate assumption is described as "based on market interest rate expectations," and the interest-rate path assumed in the baseline scenario typically coincides with the path implied by forward rates for the first several quarters, though it may deviate from market expectations in later quarters if the Bank disagrees with the apparent expectations of the markets (Norges Bank, 2005, chart 3.2).

${ }^{66}$ The members of the monetary policy committee might wish, under certain circumstances, to modify the model's default rule for the future conduct of policy because they do not regard it as correctly representing their intentions regarding near-term future policy. But this would only occur to the extent that it was in fact possible for them to agree that current conditions would justify a departure from typical policy, as in the case of the recent response to the perceived threat of deflation in the U.S., discussed above.
} 
mitment" (2001, p. 175). ${ }^{67}$ This is clearly a delicate issue in the proper explanation to the public of how the central bank's projections are to be interpreted. Yet the danger is not as great in this case as in the case of the signals regarding future policy that have recently been included in the post-meeting statements of the FOMC in the U.S. For as has just been noted, the MPC would not have to decide on a forward path for interest rates, that is then fed into the bank's model in order to generate the projections; instead, the model could incorporate an equation representing typical policy. The resulting projections would include a path for the policy rate, and to the extent to which the MPC announced that this projection represented its best judgment about how the economy was likely to evolve, it would be endorsing a forecast of its future decisions. But it would be fairly easy in this case for the discussion of the projections to include a disclaimer stating that the interest-rate projection is not intended to pre-judge the policy decisions that the MPC will actually make at later dates.

And the experience of New Zealand suggests that it is possible to reveal interestrate projections to the public without being understood to have made an advance commitment about the path of the official cash rate. Archer (2004) discusses the RBNZ's experience with the publication of a forward path for interest rates. While he mentions the possibility of the projected interest rate path's being misinterpreted "as a policy plan" (p.9), this is cited as a concern expressed to him by other central bankers, rather than as a problem that has arisen in practice in New Zealand. The main practical problem that he cites with regard to the publication of an interest-rate path is that it has not always been possible to produce a model-based projection that coincided with the policymaker's assessment of the likely future path of interest rates, in which case the quantitative projection and the discussion of future policy in the Monetary Policy Statement do not agree with one another. According to Archer, "it is noteworthy that on all such occasions, market analysts and position takers expressed frustration at the inconsistency" between the two contrasting messages regarding future policy (p. 10). The problem in such cases has been a failure of policymaker confidence in the assumptions reflected in the model-based projection. It is not clear why this problem should be greater in the case of projections regarding the path of interest rates than with other variables, though central banks may well be especially careful about what they say about this particular aspect of the future

\footnotetext{
${ }^{67}$ See also Goodhart (2005, p. 6).
} 
outlook.

Moreover, a "fan chart" for the path of interest rates ought to make it clear that the bank is not committing itself to a definite path; rather, the expected evolution will depend on a variety of contingencies that can at best be assigned probabilities. The practical possibility of communicating about this kind of uncertainty is illustrated by the way that the Bank of England currently discusses the interest-rate assumptions used in its projections "based on market interest-rate expectations." When explaining the particular interest-rate path that is assumed in the projections, the Inflation Report always takes care to note that "there is a high probability that official interest rates will not follow this path .... Given the great uncertainties, the economy will almost certainly not evolve in the way either the MPC or the markets expect," and a fan chart is presented indicating the degree of market uncertainty about interest rates at progressively longer horizons, based on the prices of options on futures contracts. ${ }^{68}$ The fan chart would seem an effective device for communication about the uncertainty around the published interest-rate path. In the case of an interest-rate path implied by a quantitative model augmented by a policy equation, it would be possible to generate the probability distributions that are plotted in the fan chart in the same way as the fan charts for inflation and output are currently generated.

Once one admits that the model used in one's projections needs an equation representing monetary policy, and not simply an interest-rate path as the specification of current and future policy, it is nonetheless possible to carry out exercises under which the projections are made to be consistent with a particular interest-rate path specified from outside the model. One might add an interest-rate equation to the model representing the central bank's reaction function (say, some version of a "Taylor rule"), and then allow the intercept term in this equation to specified arbitrarily at each future date. If one wants to produce projections consistent with a particular constant-interest-rate path, for example, one could search for the sequence of (nonconstant) intercept terms that will result in a projected path for the (endogenous) short-term nominal interest rate with exactly this feature; one could use the same approach to produce projections consistent with market expectations inferred from the term structure of interest rates. An advantage of this roundabout approach over a simple postulation of a nominal interest-rate path is that it will allow one to obtain a

\footnotetext{
${ }^{68}$ See, for example, Chart 6.1 in Bank of England (2004b, p. 41); the quotation in the text is from the same page.
} 
determinate rational-expectations equilibrium in the case of a forward-looking model of the monetary transmission mechanism, and some central banks have begun to use methods of this kind as a consequence of adopting forward-looking models. ${ }^{69}$ While this would avoid one of the problems with approaches that use an assumed interestrate path discussed above, it solves only the problem of determinacy of equilibrium; such procedures would still be vulnerable to the other criticisms offered in sections 3.1 and 3.2 .

Thus there seems no coherent alternative to an approach to inflation-forecast targeting in which the central bank's projections are produced on the basis of an assumption that the MPC is willing to make about the way in which its own future policy should endogenously respond to alternative possible future conditions. This need not involve an attempt to determine in advance the actual future path of interest rates (except, of course, in a "central case" scenario that is understood to be unlikely to actually occur), and the central bank might or might not wish to reveal much about the interest-rate path implicit in its projections for other variables. My own view is that communication about this path can help to facilitate the transmission mechanism of policy. For example, Archer (2004) concludes that the slope of the path announced by the RBNZ has effected the slope of the market yield curve in New Zealand, and an ability to influence the expectations reflected in the yield is exactly what a central bank should wish, as argued in section 1. But even if a central bank were to wish to communicate less about this aspect of its deliberations - and it must be admitted that even the RBNZ limits the amount of detail with which it describes the interest-rate path implied by its projections - it should not allow such concerns to prevent it from considering the appropriate character of future policy in its forecast-targeting exercise. And to the extent that it is concerned at all about transparency and accountability, it should not pretend to the public that its deliberations make no assumptions about future policy.

\section{Conclusion}

The increased willingness of the FOMC under the Chairmanship of Alan Greenspan to speak openly about both current policy decisions and the Committee's view of

\footnotetext{
${ }^{69}$ In the case of a purely backward-looking model of the transmission mechanism, the alternative procedure would lead to an identical outcome and would only be more cumbersome computationally.
} 
likely future policy has greatly increased the ability of markets to anticipate Fed policy. There is every reason to believe that this has been beneficial, not only from the point of view of reducing the uncertainty with which traders and other economic decisionmakers must contend, but also from that of enhancing the accuracy with which the FOMC is able to achieve the effects on the economy that it desires, by keeping the expectations of market participants more closely synchronized with its own. It is very much to be hoped that the FOMC will continue to build on this legacy under its next Chairman.

Despite the worldwide movement toward greater transparency and increased communication on the part of central banks - at least as notable in the case of the inflation-targeting central banks as it has been in the U.S. - both of the case studies just discussed indicate that there continues to be a good deal of uncertainty in central banks about the degree to which it is desirable to publicly indicate the bank's own view of the likely future path of interest rates. Nonetheless, it seems likely that in coming years central banks will develop even more effective ways of communicating about this issue.

In the case of the inflation-forecast targeting central banks, the logic of the approach to the conduct of monetary policy - and in particular, the approach to communication with the public about monetary policy decisions - that they have already adopted (and found to be largely successful) will, in my view, almost inevitably force these banks to base the projections that are at the heart of their public explanation of their policy decisions on an explicit model of their own likely future approach to policy. Their existing commitment to transparency will also require them to publicly explain the assumptions about future policy that are implicit in such projections, at least to some extent, and with suitable caveats about the fact that such policy assumptions do not represent a commitment to actually set policy in the precise way indicated by the projection. Insofar as the FOMC increases the amount that it makes public about the projections upon which its own deliberations are made which would certainly be a logical development of the current trend toward greater transparency, even if the Fed does not adopt inflation targeting — this could also become an issue that will have to be confronted at the Fed under the next Chairman.

One cannot be quite as certain about the future role of explicit indications about the expected path of interest rates of the kind with which the FOMC has experimented over the past two years. Thus far, I believe that the new approach has been a 
successful one. On the other hand, one might argue that this kind of explicit comment on the intended path of interest rates (as opposed to more general discussion of the considerations that will be taken into account in future policy decisions) is most useful under relatively special circumstances such as the ones faced by the Fed in the summer of 2003; other ways of guiding expectations about future policy might prove more suitable under more ordinary conditions. At the very least, an extension of the current policy will require the development of a more extensive lexicon of possible statements about expected future policy. But while Fed communication policy will surely develop further, the challenge of efficient communication with the markets about the future conduct of policy is one that should continue to engage the FOMC in coming years, and the relative success of recent innovations should encourage further efforts to increase the degree to which the FOMC is able to share its view of the future evolution of policy with the public. 


\section{A The Model of Morris and Shin (2002)}

Morris and Shin consider a stylized game in which each of a continuum of market participants, indexed by $i$, chooses an action $a_{i}$ (a real number) after observing a public signal $y$ and a private signal $x_{i}$. As explained in the text, the payoff of each agent $i$ depends on her own action $a_{i}$, the average action $\bar{a}$ chosen by market participants as a whole, and an unknown "fundamental" state $\theta$ (another real number). The public signal is common knowledge, and given by

$$
y=\theta+\eta
$$

where the random noise term $\eta$ is independently of the value of $\theta$, according to a normal distribution with mean zero and variance $1 / \alpha$. Each of the market participants' private signal is given by

$$
x_{i}=\theta+\epsilon_{i},
$$

where the random noise term $\epsilon_{i}$ is distributed independently of $\theta, \eta$, and each of the other $\epsilon_{j}$, according to a normal distribution with mean zero and variance $1 / \beta$. Thus $\alpha$ and $\beta$ measure the precision of the public and private signals respectively.

Morris and Shin assume that the payoff of each market participant is inversely related to a loss function of the form

$$
L^{i . M S} \equiv(1-r)\left(a_{i}-\theta\right)^{2}+r\left[E_{j}\left(a_{j}-a_{i}\right)^{2}-E_{k} E_{j}\left(a_{j}-a_{k}\right)^{2}\right],
$$

where $0<r<1$ and, as in the text, I use the notation $E_{j}(\cdot)$ for the average of some quantity over the continuum of agents indexed by $j .{ }^{70}$ This differs from the specification (1.1) given in the text by the presence of the second term inside the square brackets. The additional term is additive and independent of the action of agent $i$, so it has no effect on equilibrium behavior. It matters only for the evaluation of welfare, and is introduced by Morris and Shin to justify their assumption that the dispersion of actions across market participants is of no consequence for welfare, even though it is a concern that is given considerable weight in the decisions of individuals.

Under these preferences (whether written as in (1.1) or as in (A.1)), the optimal action of agent $i$ will be given by

$$
a_{i}^{*}=E\left[r \bar{a}+(1-r) \theta \mid y, x_{i}\right],
$$

\footnotetext{
${ }^{70}$ Morris and Shin write integrals for this operator.
} 
$i$ 's estimate of a weighted average of the fundamental state $\theta$ and the average action of others $\bar{a}$. (Here $E[\cdot \mid \cdot]$ is the conditional expectation operator, averaging over possible realizations of $\theta$ and the random signals.) Thus a higher value of $r$ implies a greater tendency to choose an action similar to what one guesses that others are doing (greater strategic complementarity).

Under the assumption of prior beliefs about $\theta$ given by an improper uniform prior on the real line, an agent's optimal estimate of the fundamental state after observing both private and public signals will be

$$
E\left[\theta \mid y, x_{i}\right]=\frac{\alpha}{\alpha+\beta} y+\frac{\beta}{\alpha+\beta} x_{i}
$$

a weighted average of the two signals with weights that depend on the relative precisions of the signals. One can then show that the equilibrium action of each market participant will be given by

$$
a_{i}^{*}=\frac{\alpha y+\beta(1-r) x_{i}}{\alpha+\beta(1-r)}
$$

Expression (A.2) shows how the weight that market participants put on their private information decreases as a result of an increase in the precision $\alpha$ of the public signal.

Morris and Shin measure social welfare by the negative of the social loss function

$$
L^{s o c, M S}=\frac{1}{1-r} E_{i} L^{i, M S}
$$

which is easily seen to correspond to the expression (1.2) in the text. It then follows from the description (A.2) of equilibrium behavior that

$$
\Lambda^{M S} \equiv E\left[L^{s o c, M S} \mid \theta\right]=\frac{\alpha+\beta(1-r)^{2}}{[\alpha+\beta(1-r)]^{2}} .
$$

The key result of Morris and Shin is that the function on the right-hand side of (A.3) is not necessarily decreasing in $\alpha$, for given values of $\beta$ and $r$. In particular, one can show that $\partial \Lambda^{M S} / \partial \alpha>0$ if and only if

$$
\frac{\alpha}{\beta}<(1-r)(2 r-1) \text {. }
$$

Since the right-hand side of (A.4) is positive for all $1 / 2<r<1$, there exist parameter configurations that satisfy (A.4). Hence it is possible to construct examples in which 
a (small enough) increase in the precision of the public signal would increase expected social losses, under the Morris-Shin measure. As noted in the text, however, condition (A.4) is fairly stringent. Svensson (2005) points out that the right-hand side of (A.4) is no greater than $1 / 8$ for any value of $r$; hence the perverse case cannot arise unless $\alpha<\beta / 8$. Moreover, the right-hand side is only positive if $r>1 / 2$, so the perverse case does not arise, even when $\alpha$ is much smaller than $\beta$, unless $r>1 / 2$, so that the weight on the conformity-with-others objective in market participants' preferences is greater than the weight on the conformity-with-fundamentals objective.

The possibility of a perverse case also depends on the (completely unmotivated) inclusion of the final term in the individual loss function (A.1). Suppose that one instead represents individual preferences by the loss function (1.1) proposed in the text, and uses as a social loss function the corresponding population average,

$$
L^{s o c}=\frac{1}{1-r} E_{i} L^{i}
$$

Equilibrium actions are again given by (A.2), but the implied expected level of social losses is now

$$
\Lambda \equiv E\left[L^{s o c} \mid \theta\right]=\frac{\alpha+\beta\left(1-r^{2}\right)}{[\alpha+\beta(1-r)]^{2}} .
$$

The right-hand side of (A.5) is easily seen to be a globally decreasing function of $\alpha$, for any values of $\beta$ and $r$. Thus in this case, the release of a more precise estimate by the public authority will necessarily improve social welfare, regardless of how imprecise the estimate may be that it is possible for the authority to release, and of how great may be the concern of market participants to behave as others do. 


\section{References}

Adam, Klaus, and Roberto M. Billi, "Optimal Monetary Policy under Commitment with a Zero Bound on Nominal Interest Rates," unpublished, University of Frankfurt, August 2003.

Amato, Jeffery D., Stephen Morris, and Hyun Song Shin, "Communication and Monetary Policy," Oxford Review of Economic Policy 18: 495-503 (2002).

Amato, Jeffery D., and Hyun Song Shin, "Public and Private Information in Monetary Policy Models," BIS working paper no. 138, July 2003.

Angeletos, George-Marios, and Alessandro Pavan, "Transparency of Information and Coordination in Economies with Investment Complementarities," American Economic Review 94(2): 91-98 (2004).

Archer, David, "Communication with the Public," unpublished, Reserve Bank of New Zealand, May 2004.

Bank of England, Inflation Report, February 2004a.

- - - Inflation Report, August 2004b.

Bernanke, Ben S., "Central Bank Talk and Monetary Policy," remarks at the Japan Society corporate luncheon, New York, October 7, 2004.

Bernanke, Ben S., Vincent R. Reinhart, and Brian P. Sack, "Monetary Policy Alternatives at the Zero Bound: An Empirical Assessment," Brookings Papers on Economic Activity 2004:2, pp. 1-78.

Blinder, Alan, Charles Goodhart, Philipp Hildebrand, David Lipton, and Charles Wyplosz, How Do Central Banks Talk? Geneva Report on the World Economy no. 3, International Center for Monetary and Banking Studies, 2001.

Bullard, James, and Kaushik Mitra, "Learning about Monetary Policy Rules," Journal of Monetary Economics 49: 1105-1129 (2002).

Clarida, Richard, Jordi Gali and Mark Gertler (1999), "The Science of Monetary Policy: A New Keynesian Perspective," Journal of Economic Literature 37: 1661-1707.

Demiralp, Selva, and Oscar Jorda, "The Announcement Effect: Evidence from 
Open Market Desk Data," Federal Reserve Bank of New York Economic Policy Review 8: 29-48 (2002).

Economist, "It's Not Always Good to Talk," July 22, 2004, page 71.

Eggertsson, Gauti B., and Michael Woodford, "The Zero Bound on Interest Rates and Optimal Monetary Policy," Brookings Papers on Economic Activity 2003:1, pp. 139-233.

Ehrmann, Michael, and Marcel Fratzscher, "Transparency, Disclosure and the Federal Reserve," ECB working paper no. 457, March 2005.

Eusepi, Stefano, "Central Bank Transparency under Model Uncertainty," unpublished, Federal Reserve Bank of New York, January 2005.

Fujiki, Hiroshi, and Shigenori Shiratsuka, "Policy Duration Effect under the Zero Interest Rate Policy in 1999-2000: Evidence from Japan's Money Market Data," Bank of Japan Monetary and Economic Studies 20(1): 1-31 (2002).

Giannoni, Marc P. and Michael Woodford, "Optimal Interest-Rate Rules: I. General Theory," NBER working paper no. 9419, December 2002.

Goodhart, Charles A.E., "Monetary Transmission Lags and the Formulation of the Policy Decision on Interest Rates," Federal Reserve Bank of St. Louis Review, July/August 2001, pp. 165-181.

- - - "The Interest Rate Conditioning Assumption," unpublished, London School of Economics, May 2005.

Gurkaynak, Refet S., "Using Federal Funds Futures Contracts for Monetary Policy Analysis," Federal Reserve Board, Finance and Economics Discussion Series working paper no. 2005-29, June 2005.

_- - B Brian Sack, and Eric Swanson, "Do Actions Speak Louder than Words? The Response of Asset Prices to Monetary Policy Actions and Statements," International Journal of Central Banking 1: 55-93 (2005).

Hellwig, Christian, "Heterogeneous Information and the Benefits of Transparency," unpublished, UCLA, December 2004.

Honkapohja, Seppo, and Kaushik Mitra, "Problems in Inflation Targeting Based on Constant Interest Rate Projections," unpublished, University of Helsinki, August 2003. 
Issing, Otmar, "Communication, Transparency, Accountability: Monetary Policy in the Twenty-First Century," Federal Reserve Bank of St. Louis Review $87(2$, pt. 1), pp. 65-83 (2005).

Iwamura, Mitsuri, Takeshi Kudo, and Tsutomu Watanabe, "Monetary and Fiscal Policy in a Liquidity Trap: The Japanese Experience 1999-2004," unpublished, Waseda University, August 2004.

Jansson, Per, and Anders Vredin, "Forecast-Based Monetary Policy: The Case of Sweden," International Finance 6: 349-380 (2003).

Jung, Taehun, Yuki Teranishi, and Tsutomu Watanabe, "Optimal Monetary Policy at the Zero-Interest-Rate Bound," Journal of Money, Credit and Banking, forthcoming 2005.

King, Mervyn, "What Has Inflation Targeting Achieved?" in B.S. Bernanke and M. Woodford, eds., The Inflation Targeting Debate, Chicago: University of Chicago Press, 2005a.

- - - " "Monetary Policy: Practice Ahead of Theory," 2005 Mais Lecture, delivered at Cass Business School, London, May 17. 2005b.

Kohn, Donald L., "Central Bank Communication," remarks at the annual meeting of the American Economics Association, Philadelphia, January 9, 2005.

Krugman, Paul (1998), "It's Baaack! Japan's Slump and the return of the Liquidity Trap," Brookings Papers on Economic Activity 1998:2, pp. 137-187.

Kydland, Finn E., and Edward C. Prescott, "Rules Rather than Discretion: The Inconsistency of Optimal Plans," Journal of Political Economy 85: 473-491 (1977).

Lange, Joe, Brian Sack, and William Whitesell, "Anticipations of Monetary Policy in Financial Markets," Federal Reserve Board, FEDS paper no. 2001-24, April 2001.

Leitemo, Kai, "Targeting Inflation by Constant-Interest-Rate Forecasts," Journal of Money, Credit and Banking 35: 609-26 (2003).

Morris, Stephen, and Hyun Song Shin, "The Social Value of Public Information," American Economic Review 92: 1521-34 (2002).

Norges Bank, Inflation Report, June 2005. 
Oda, Nobuyuki, and Kazuo Ueda, "The Effects of the Bank of Japan's Zero Interest Rate Commitment and Quantitative Monetary Easing on the Yield Curve: A Macro-Finance Approach," Bank of Japan Working Paper no. 05-E-6, April 2005.

Orphanides, Athanasios, and John C. Williams, "Imperfect Knowledge, Inflation Expectations, and Monetary Policy," in B.S. Bernanke and M. Woodford, eds., The Inflation Targeting Debate, Chicago: University of Chicago Press, 2005.

Poole, William, "Remarks: Panel on 'After Greenspan: Whither Fed Policy?"” remarks delivered at the Western Economics Association International conference, San Francisco, California, July 6, 2005.

Preston, Bruce, "Learning about Monetary Policy Rules when Long-Horizon Forecasts Matter," International Journal of Central Banking, forthcoming 2005.

Roca, Mauro, "Transparency and Monetary Policy with Imperfect Common Knowledge," unpublished, Columbia University, February 2005.

Romer, Christina D., and David H. Romer, "Federal Reserve Private Information and the Behavior of Interest Rates," American Economic Review 90: 429457 (2000).

Sargent, Thomas J., and Neil Wallace, "'Rational' Expectations, the Optimal Monetary Instrument, and the Optimal Money Supply Rule," Journal of Political Economy 83: 241-254 (1975).

Sugo, Tomohiro, and Yuki Teranishi, "How Should Optimal Monetary Policy Rules Be Designed in a Low Inflation Era?" unpublished, Bank of Japan, March 2005.

Svensson, Lars E.O., "Inflation Targeting as a Monetary Policy Rule," Journal of Monetary Economics 43: 607-654 (1999).

_- _- "The Inflation Forecast and the Loss Function," in P. Mizen, ed., Central Banking, Monetary Theory and Practice: Essays in Honour of Charles Goodhart, vol. 1, Edward Elgar, 2003.

_- - - "The Magic of the Exchange Rate: Optimal Escape from a Liquidity Trap in Small and Large Open Economies," unpublished, Princeton University, July 2004. 
_- _-, "Social Value of Public Information: Morris and Shin (2002) is Actually Pro Transparency, Not Con," unpublished, Princeton University, February 2005.

- - - and Michael Woodford, "Implementing Optimal Policy through InflationForecast Targeting," in B.S. Bernanke and M. Woodford, eds., The Inflation Targeting Debate, Chicago: Univ. of Chicago Press, 2005.

Sveriges Riksbank, Inflation Report, First Quarter, 2005.

Vickers, John, "Inflation Targeting in Practice: The U.K. Experience," Bank of England Quarterly Bulletin, November 1998.

Woodford, Michael, "Monetary Policy in the Information Economy," in Economic Policy for the Information Economy, Kansas City: Federal Reserve Bank of Kansas City, 2001.

- - - Interest and Prices: Foundations of a Theory of Monetary Policy, Princeton: Princeton University Press, 2003.

__ _- "Inflation Targeting and Optimal Monetary Policy," Federal Reserve Bank of St. Louis Economic Review, July/August 2004, pp.15-41. 